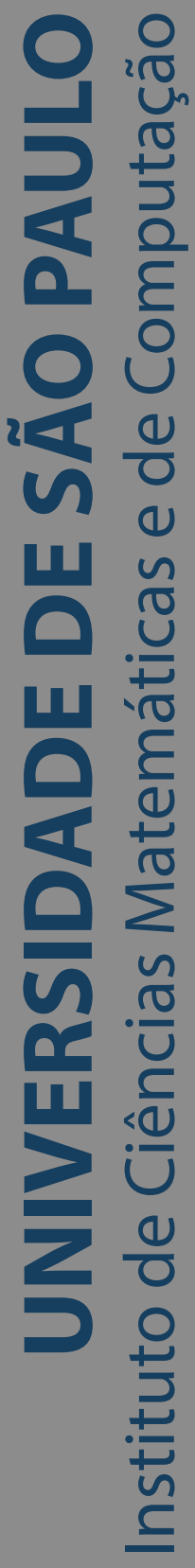

Reconhecimento de movimentos de cães utilizando um acelerômetro e redes neurais artificiais

\title{
Camila Cocolo
}

Dissertação de Mestrado do Programa de Mestrado Profissional em Matemática, Estatística e Computação Aplicadas à Indústria (MECAI) 

Data de Depósito:

Assinatura:

\section{Camila Cocolo}

\section{Reconhecimento de movimentos de cães utilizando um acelerômetro e redes neurais artificiais}

\footnotetext{
Dissertação apresentada ao Instituto de Ciências Matemáticas e de Computação - ICMC-USP, como parte dos requisitos para obtenção do título de Mestra - Mestrado Profissional em Matemática, Estatística e Computação Aplicadas à Indústria. EXEMPLAR DE DEFESA

Área de Concentração: Matemática, Estatística e Computação

Orientadora: Profa. Dra. Gleici da Silva Castro Perdoná
} 
Ficha catalográfica elaborada pela Biblioteca Prof. Achille Bassi e Seção Técnica de Informática, ICMC/USP, com os dados inseridos pelo(a) autor(a)

Cocolo, Camila

Reconhecimento de movimentos de cães utilizando um acelerômetro e redes neurais artificiais / Camila Cocolo; orientadora Gleici da Silva Castro Perdoná. -- São Carlos, 2020.

$78 \mathrm{p}$.

Dissertação (Mestrado - Programa de Pós-Graduação em Mestrado Profissional em Matemática, Estatística e Computação Aplicadas à Indústria) -- Instituto de Ciências Matemáticas e de Computação, Universidade de São Paulo, 2020.

1. Classificação de movimentos. 2. Acelerômetro. 3. Cães. 4. CNN. I. da Silva Castro Perdoná, Gleici, orient. II. Título.

Bibliotecários responsáveis pela estrutura de catalogação da publicação de acordo com a AACR2: Gláucia Maria Saia Cristianini - CRB - 8/4938

Juliana de Souza Moraes - CRB - 8/6176 


\section{Camila Cocolo}

\section{Recognition of dog movements using an accelerometer and artificial neural networks}

Dissertation submitted to the Institute of Mathematics and Computer Sciences - ICMC-USP - in accordance with the requirements of the Professional Master's Program in Mathematics Statistics and Computing Applied to Industry, for the degree of Master in Science. EXAMINATION BOARD PRESENTATION COPY

Concentration Area: Mathematics, Statistics and Computing

Advisor: Profa. Dra. Gleici da Silva Castro Perdoná 

Este trabalho é dedicado a todos os animais. 

À professora Gleici da Silva de Castro Perdoná pelos ensinamentos, discussões, apoio, paciência e entusiasmo em trabalhar com um assunto inovador, que é o reconhecimento do movimento dos cães.

À minha mãe Marci, ao meu pai Claudecir e minha irmã Juliana que sempre me incentivaram nos estudos e que proporcionaram toda a estrutura emocional, espiritual e logística para que a realização do Mestrado e dessa pesquisa fosse possível.

À minha amiga Regiane Hirata, pelas contribuições essenciais para esta pesquisa e por compartilhar a sua paixão e curiosidade pelos cães.

À escola de Engenharia de São Carlos e ao Instituto De Ciências Matemáticas e de Computação, todos os professores, técnicos, assistentes e secretárias que contribuíram durante minha formação.

Aos colegas da Logicalis, que me incentivaram nos estudos e possibilitaram a flexibilização no trabalho para que eu pudesse assistir às aulas do mestrado.

A todos os cães que contribuíram para esta pesquisa, possibilitando a descoberta de algo novo e que tornaram este trabalho possível. Agradeço também aos tutores que se disponibilizaram a fazer as observações de comportamento.

A todos que, direta ou indiretamente, contribuíram com esta pesquisa e com o desenvolvimento do meu Mestrado, meus sinceros agradecimentos. 

"Chegará o dia em o homem conhecerá o íntimo dos animais. Neste dia, um crime contra um animal será considerado um crime contra a humanidade." 



\section{RESUMO}

COCOLO, C. Reconhecimento de movimentos de cães utilizando um acelerômetro e redes neurais artificiais. 2020. 78 p. Dissertação (Mestrado - Mestrado Profissional em Matemática, Estatística e Computação Aplicadas à Indústria) - Instituto de Ciências Matemáticas e de Computação, Universidade de São Paulo, São Carlos - SP, 2020.

A classificação dos movimentos de cães utilizando dados de acelerômetro é uma área ainda pouco explorada no Brasil, mas de grande importância para o acompanhamento da saúde e bem estar destes animais. Este trabalho propõe um método de classificação de movimentação dos cães, a partir de um acelerômetro triaxial, e utilização de três arquiteturas de redes neurais artificiais: Rede Neural Convolucional (CNN), Rede Neural Convolucional associada a Long Short Term Memory (CNN-LSTM) e ConvLSTM. A metodologia foi desenvolvida instalando um pingente contendo o acelerômetro na coleira de 8 cachorros, que coletava dados em uma frequência de $10 \mathrm{~Hz}$. Para avaliar o desempenho das redes neurais foi considerado o coeficiente de Matthews, que é um indicador muito utilizado na área de bioinformática. A arquitetura com melhor desempenho foi a ConvLSTM, que apresentou um coeficiente de Matthews de 0,79 no conjunto de teste.

Palavras-chave: Classificação de movimentos, Acelerômetro, Cães, CNN, CNN LSTM, ConvLSTM. 



\section{ABSTRACT}

COCOLO, C. Recognition of dog movements using an accelerometer and artificial neural networks. 2020. 78 p. Dissertação (Mestrado - Mestrado Profissional em Matemática, Estatística e Computação Aplicadas à Indústria) - Instituto de Ciências Matemáticas e de Computação, Universidade de São Paulo, São Carlos - SP, 2020.

Classification of dogs movements by using data collected from accelerometers is an area little explored in Brazil, but this is of great importance to monitor health and well-being of these animals. This work proposes a method to classify the movement of dogs using a triaxial accelerometer, and the use of three artificial neural network architectures: Convolutional Neural Network (CNN), Convolutional Neural Network associated with Long Short Term Memory ( CNN-LSTM) and ConvLSTM. The methodology was developed by installing a pendant that contains the accelerometer on the collar of $8 \mathrm{dogs}$, and it presents data collected at a frequency of $10 \mathrm{~Hz}$. To evaluate the neural network performance the Matthews coefficient was considered, which is an widely used indicator in the area of bioinformatics. The best performing architecture was ConvLSTM, which had a Matthews coefficient of 0.79 on the test set.

Keywords: Movement classification, Accelerometer, Dogs, CNN, CNN LSTM, ConvLSTM. 



\section{LISTA DE ILUSTRAÇÕES}

Figura 1 - Estrutura simplificada de um acelerômetro . . . . . . . . . . . . . 31

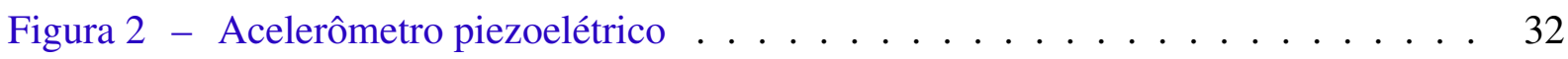

Figura 3 - Acelerômetro piezoresistivo . . . . . . . . . . . . . 33

Figura 4 - Acelerômetro capacitivo . . . . . . . . . . . . . 34

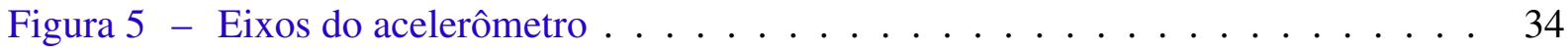

Figura 6 - Dispositivo Whistle Go . . . . . . . . . . . . . 36

Figura 7 - FitBark Dog Activity Monitor . . . . . . . . . . . . 37

Figura 8 - LINK AKC Smart Dog Collar . . . . . . . . . . . . . . . . 37

Figura 9 - PetPace Smart-Sensing Collar . . . . . . . . . . . . . . 38

Figura 10 - Neurônio artificial . . . . . . . . . . . . . . . . . . . . . 40

Figura 11 - Exemplos de funções de ativação . . . . . . . . . . . . . . . . . . . . . . . . . . . . . . . . . .

Figura 12 - Rede Neural Multicamadas . . . . . . . . . . . . . . . . . . 41

Figura 13 - Campos receptivos locais no córtex visual _ . . . . . . . . . . . . . 42

Figura 14 - Exemplo de arquitetura de uma CNN . . . . . . . . . . . . . . . 43

Figura 15 - Operação de Convolução . . . . . . . . . . . . . . . . . . . . . 43

Figura 16 - Conectividade esparsa da rede CNN e conectividade global da rede MLNN . 44

Figura 17 - Campos receptivos locais da CNN . . . . . . . . . . . . . . . 45

Figura 18 - CNN com três mapas de características . . . . . . . . . . . . . . 45

Figura 19 - Camadas convolucionais . . . . . . . . . . . . . . . 46

Figura 20 - Exemplo de same padding . . . . . . . . . . . . . . . . . . 46

Figura 21 - Exemplo de max pooling com filtro $2 \times 2$ e stride igual a $2 \ldots$. . . . . . . . 47

Figura 22 - Exemplo de rede sem e com dropout . . . . . . . . . . . . . . . . . . 48

Figura 23 - Camadas totalmente conectada composta por 3 camadas (flatten, escondida e

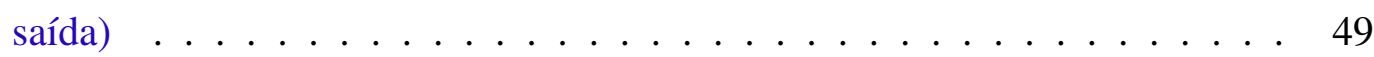

Figura 24 - Um neurônio recorrente (à esquerda), desenrolado através do tempo (à direita) 50

Figura 25 - Célula LSTM . . . . . . . . . . . . . . . . . . . 50

Figura 26 - Célula ConvLSTM . . . . . . . . . . . . . . . 51

Figura 27 - Matriz de Confusão . . . . . . . . . . . . . . . . . . . . 52

Figura 28 - Diagrama simplificado do sistema de aquisição de dados . . . . . . . . . . 56

Figura 29 - Posicionamento dos eixos do acelerômetro na coleira do cão . . . . . . . 57

Figura 30 - Ilustração do aplicativo utilizado para a classificação dos movimentos . . . . 58

Figura 31 - Segmentação dos dados em janelas de 60 amostras com $50 \%$ de sobreposição 59

Figura 32 - Sinais representativos dos movimentos . . . . . . . . . . . . 62 
Figura 33 - Diferenças entre as redes propostas . . . . . . . . . . . . 63

Figura 34 - Desempenho considerando a variação no tamanho da janela . . . . . . . . . 66

Figura 35 - Desempenho considerando a variação na quantidade de camadas convolucionais 67

Figura 36 - Desempenho considerando a variação no tamanho do filtro . . . . . . . . 67 
Quadro 1 - Descrição dos cães participantes deste estudo . . . . . . . . . . . . 57

Quadro 2 - Descrição dos cinco comportamentos analisados . . . . . . . . . . . 58

Quadro 3 - Movimentos reconhecidos pelo sistema . . . . . . . . . . . 62

Quadro 4 - Detalhes da arquitetura da rede CNN . . . . . . . . . . . 68

Quadro 5 - Detalhes da arquitetura da rede CNN LSTM . . . . . . . . . . . . . 69

Quadro 6 - Detalhes da arquitetura da rede ConvLSTM . . . . . . . . . . . . 70 



\section{LISTA DE TABELAS}

Tabela 1 - Desempenho das redes neurais considerando a variação dos parâmetros . . . 64

Tabela 2 - Matriz de confusão para a rede CNN . . . . . . . . . . . . . . . . . 69

Tabela 3 - Matriz de confusão para a rede CNN LSTM . . . . . . . . . . . . 70

Tabela 4 - Matriz de confusão para a rede ConvLSTM . . . . . . . . . . . . 71

Tabela 5 - Análise comparativa entre os métodos . . . . . . . . . . . 71 



\section{LISTA DE ABREVIATURAS E SIGLAS}

$\begin{array}{ll}\text { CNN } & \text { Redes Neurais Convolucionais } \\ \text { FCI } & \text { Federação Cinológica Internacional } \\ \text { IBGE } & \text { Instituto Brasileiro de Geografia e Estatística } \\ \text { LSTM } & \text { Memória Longa de Curto Prazo } \\ \text { MCC } & \text { Coeficiente de Correlação de Matthews } \\ \text { MLNN } & \text { Rede Neural Multicamadas } \\ \text { PNS } & \text { Pesquisa Nacional de Saúde } \\ \text { RNA } & \text { Redes Neurais Artificiais } \\ \text { RNN } & \text { Redes Neurais Recorrentes }\end{array}$



INTRODUÇÃO $\ldots \ldots \ldots \ldots \ldots \ldots \ldots \ldots$

1.1

Motivação 25

1.2

Objetivo Geral 27

1.3

Objetivos Específicos 27

$2.1 \quad$ A importância da movimentação canina . . . . . . . . . . 29

$2.2 \quad$ Utilização do acelerômetro no estudo do movimento . . . . . . . . 30

2.2.1 Princípios básicos de funcionamento do acelerômetro . . . . . . 31

2.2.1.1 Acelerômetro piezoelétrico . . . . . . . . . . . . . . . . . . 32

2.2.1.2 Acelerômetro piezoresistivo . . . . . . . . . . . . . . 33

2.2.1.3 Acelerômetro capacitivo . . . . . . . . . . . . . . . . 33

2.2.1.3.1 Acelerômetro capacitivo utilizado neste trabalho . . . . . . . . . . . 34

3 DISPOSITIVOS COMERCIAIS PARA MONITORAÇÃO DE CÃES 35

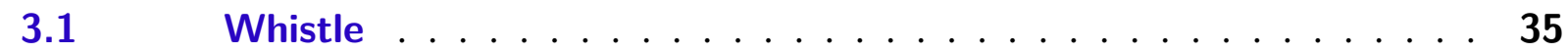

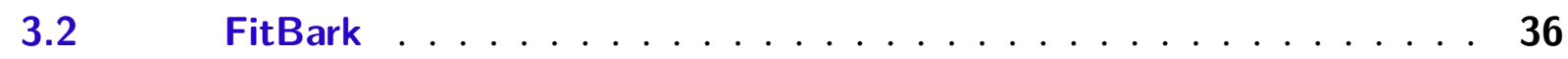

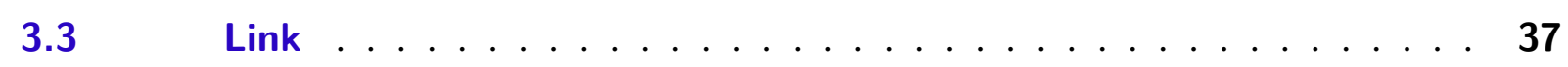

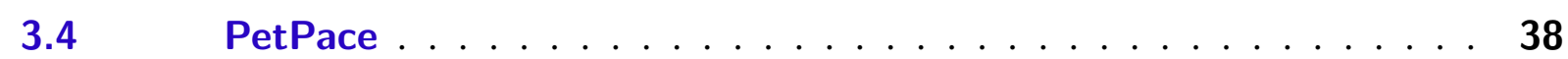

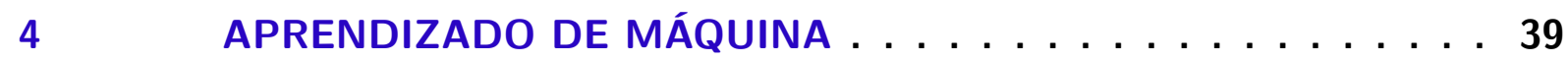

$4.1 \quad$ Redes Neurais Artificiais . . . . . . . . . . . . . . 39

4.1.1 Rede Neural Multicamadas . . . . . . . . . . . . . . . . 41

4.1.2 Redes Neurais Convolucionais . . . . . . . . . . . . . . . . . . 42

4.1.2.1 Camada Convolucional . . . . . . . . . . . . . . . . . 43

4.1.2.2 Função de ativação . . . . . . . . . . . . . . . . . . 46

4.1.2.3 Camada de Pooling . . . . . . . . . . . . . . . . . . . . . 47

4.1 .2 .4 Dropout . . . . . . . . . . . . . . . . . . . 47

4.1.2.5 Camada totalmente conectada . . . . . . . . . . . . . . 48

4.1.3 Redes Neurais Recorrentes . . . . . . . . . . . . . . . . 49

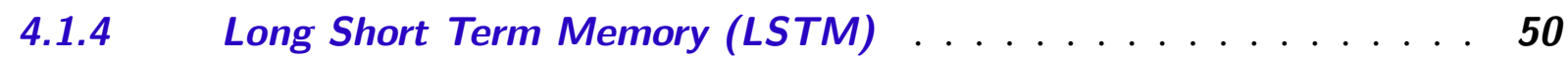

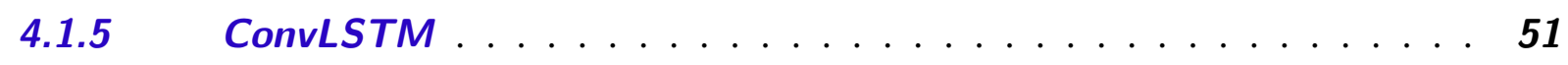

$4.2 \quad$ Métricas de avaliação dos resultados . . . . . . . . . . 51 
4.2.1 Matriz de Confusão . . . . . . . . . . . . . . . . . 52

4.2.2 Acurácia ....................... 53

$4.2 .3 \quad$ Precisão . . . . . . . . . . . . . . . 53

4.2 .4 Sensibilidade . . . . . . . . . . . . . . 53

$4.2 .5 \quad$ F1 Score . . . . . . . . . . . . . . . . . . . 53

4.2.6 Coeficiente de correlação de Matthews . . . . . . . . . . . . 53

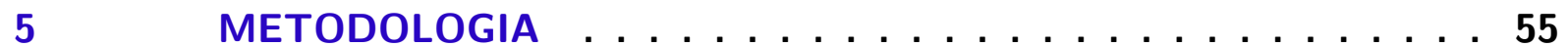

$5.1 \quad$ Sistema de aquisição e transmissão dos dados . . . . . . . . . . . 55

$5.2 \quad$ Cães analisados . . . . . . . . . . . . . . . 57

$5.3 \quad$ Protocolo de coleta de dados . . . . . . . . . . . . . . 57

$5.4 \quad$ Amostragem dos movimentos . . . . . . . . . . . . . . 58

$5.5 \quad$ Segmentação dos dados . . . . . . . . . . . . . . . 59

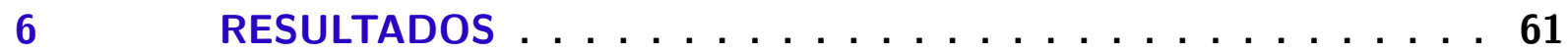

$6.1 \quad$ Pré-processamento dos dados . . . . . . . . . . . . 61

$6.2 \quad$ Arquitetura das redes neurais utilizadas . . . . . . . . . . . . . 63

6.2.1 Treinamento e teste da CNN . . . . . . . . . . . . . . . 64

6.2.1.1 Análise da variação dos parâmetros da CNN . . . . . . . . . . . . . . . 64

6.2 .1 .1 Tamanho da janela . . . . . . . . . . . . . . . . . 66

6.2.1.1.2 Número de camadas convolucionais . . . . . . . . . . . . . . 66

6.2 .1 .3 Tamanho do filtro . . . . . . . . . . . . . . . . 67

6.2.2 Treinamento e teste da CNN LSTM . . . . . . . . . . . . . . 69

6.2.3 Treinamento e teste da da ConvLSTM . . . . . . . . . . . . . . . . 70

6.2.4 Resultados e comparação entre as diferentes redes treinadas . . . . 71

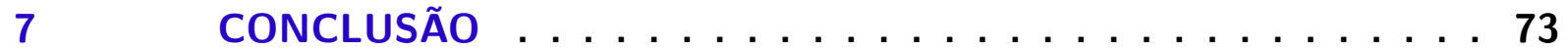

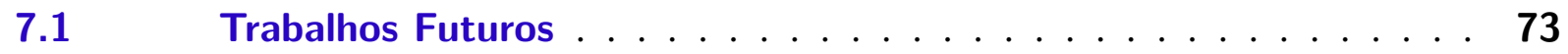

7.1.1 Utilizar câmeras para filmar o comportamento dos cães . . . . . . . 73

7.1.2 Aumentar a variedade de movimentos reconhecidos . . . . . . . . 74

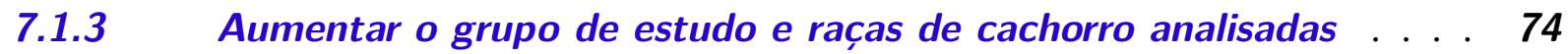

REFERÊNCIAS . . . . . . . . . . . . . . . . . 75 


\section{1}

\section{INTRODUÇÃO}

\subsection{Motivação}

Humanos e cães convivem em estreita proximidade há milhares de anos, possuindo vínculos emocionais e sociais. No Brasil, segundo a Pesquisa Nacional de Saúde (PNS) realizada pelo Instituto Brasileiro de Geografia e Estatística (IBGE) em 2013, estima-se que 44,3\% dos domicílios possuam pelo menos um cachorro, o que equivale a 28,9 milhões de lares no país, e uma população total de cães estimada em 52,2 milhões (IBGE, 2014). Dada a grande presença e importância que estes animais possuem nas atividades humanas, a utilização de acelerômetros para reconhecimento dos movimentos caninos em aplicações de monitoração de bem estar e detecção de problemas de saúde é uma área de pesquisa crescente e desafiadora.

O acelerômetro é um sensor inercial capaz de medir a aceleração, seja ela estática, como a força da gravidade, ou dinâmica, como a causada por alguma movimentação ou vibração. Este sensor tem sido utilizado na medicina veterinária como uma forma de medir objetivamente o nível de atividade em cães (MICHEL; BROWN, 2011) e distinguir diferentes atividades realizadas (UIJL et al., 2017). Além disso, algumas condições clínicas também podem ser detectadas pelo acelerômetro como diabetes (GUPTILL; GLICKMAN; GLICKMAN, 2013), problemas dermatológicos (CARON-LORMIER et al., 2016), infecção de ouvido (FORSYTHE, 2016) e distúrbios comportamentais, como ansiedade de separação (BORCHELT; VOITH, 1982).

De modo geral, os cães sentem dor da mesma forma que os seres humanos, mas não costumam demonstrar rapidamente e quando dão sinais eles são geralmente sutis. Dessa forma, os tutores não são capazes de identificar o início de doenças e muitas vezes só levam os cães para consultas veterinárias quando o animal já está em estado crítico. A detecção precoce de que algo está errado com o cão permite que o tutor procure o veterinário no estágio inicial da doença, o que contribui para aumentar as chances de cura e para o bem-estar do animal (MILIONE, 2019). Os acelerômetros são capazes de detectar mudanças em atividades ou comportamentos específicos 
dos cães, indicando sinais relacionados a possíveis eventos adversos à saúde (RHODIN et al., 2017).

Para que os acelerômetros possam ser utilizados na monitoração dos movimentos dos cães de forma não obstrutiva, estes dispositivos precisam ser pequenos, leves, energeticamente suficientes e baratos (GERENCSÉR et al., 2013), também é recomendável que sejam resistentes e à prova d'água para uso externo. Outro ponto relevante é a região do corpo onde o acelerômetro é instalado, pois ele deve ser capaz de capturar sinais de movimentos distintos sem interferir na execução das atividades. Uma forma conveniente de utilizar acelerômetros em cães é colocando-o acoplado à coleira, desta forma ele torna-se um wearable (sensor vestível) não invasivo para monitoração do cão.

No futuro, os dados provenientes destes wearables permitirão aos veterinários medir objetivamente os dados de saúde e bem-estar dos animais, além de serem utilizados para vigilância digital de doenças, cuidados pós-operatórios remotos e eficácia do tratamento de distúrbios. Os dados consolidados podem ser reutilizados para diversos propósitos como para fins educacionais, de pesquisa ou comerciais (GERENCSÉR et al., 2013).

Uma vez que os dados inerciais são capturados pelo acelerômetro é preciso realizar um tratamento sobre eles para que possam classificar os diferentes movimentos realizados pelo cachorro. Uma possível abordagem seria a utilização de aprendizado de máquina nãosupervisionado, onde os algoritmos de reconhecimento de padrões identificam diferentes estados diretamente dos dados do acelerômetro. Entretanto, essa tarefa é muito desafiadora e pode ser simplificada com a utilização de algoritmos de aprendizagem supervisionada, que utilizam um conjunto de treinamento com movimentos classificados e aprendem a relacionar estas classificações com os sinais do acelerômetro (TATLER; CASSEY; PROWSE, 2018).

As Redes Neurais Artificiais (RNA) podem aplicar aprendizagem supervisionada desde que seja indicada a resposta desejada para o padrão de entrada. A utilização de Redes Neurais Convolucionais (CNN) é particularmente muito indicada para a análise de classificação de movimentos, pois estas redes têm a capacidade de extrair características dos dados e relacioná-las com cada movimento. Outro tipo de rede neural considerada para este estudo é a Memória Longa de Curto Prazo (LSTM) que é uma rede caracterizada por possuir uma memória para modelar dependências temporais. A combinação de CNNs e LSTMs em uma estrutura unificada já ofereceu bons resultados no domínio de reconhecimento de fala, onde a modelagem de informações temporais é necessária (SAINATH et al., 2015), pois esse tipo de arquitetura é capaz de capturar dependências de tempo em características extraídas por operações convolucionais.

Inspirado pelos pontos mencionados, o objetivo desta pesquisa é propor um sistema de reconhecimento automático de movimentos caninos utilizando um único sensor acelerômetro instalado na coleira do cachorro. Para o reconhecimento do movimento são explorados algoritmos de aprendizado profundo como a CNN e LSTM, que são redes capazes de reconhecer os cinco estados elementares da rotina dos cachorros abordados neste estudo, sendo eles: estar andando, 
correndo, comendo $\backslash$ bebendo, latindo ou sentado.

\subsection{Objetivo Geral}

Este trabalho tem como objetivo utilizar um acelerômetro acoplado na coleira do cachorro para coletar dados de aceleração, e explorar arquiteturas de Redes Neurais Artificiais para reconhecer movimentos específicos da rotina do cão.

\subsection{Objetivos Específicos}

- Coletar amostras de aceleração obtidas por um único acelerômetro triaxial instalado na coleira de cães de diferentes raças, idades e sexo;

- Realizar o processamento das amostras de aceleração para o treinamento de uma Rede Neural Convolucional;

- Avaliar o desempenho da CNN, da CNN combinada com a LSTM e da rede ConvLSTM para o reconhecimento de movimentos de cães.

\subsection{Organização do Trabalho}

O Capítulo 2 apresenta características dos comportamentos e da movimentação dos cães, mostra o funcionamento do acelerômetro e indica como este dispositivo pode ser utilizado para o reconhecimento de movimentos dos cães.

O Capítulo 3 apresenta dispositivos comerciais utilizados na monitoração de cães e que possuem o acelerômetro como base de funcionamento.

O Capítulo 4 abrange os fundamentos de Redes Neurais Convolucionais, Redes Neurais Convolucionais combinadas com LSTM, e redes ConvLSTM utilizadas neste trabalho. E também apresenta as definições de métricas de resultados utilizadas para avaliar o desempenho das redes neurais.

O Capítulo 5 descreve a metodologia utilizada para o desenvolvimento deste trabalho.

O Capítulo 6 apresenta os resultados obtidos com as diferentes topologias de redes neurais utilizadas.

O Capítulo 7 trás as conclusões do trabalho e indica possibilidades para o desenvolvimento de trabalhos futuros. 



\section{MONITORAÇÃO DE MOVIMENTOS \\ CANINOS}

Neste capítulo serão apresentados aspectos sobre como o comportamento e movimentação dos cães podem ser utilizados para interpretar seu humor, suas intenções e desejos. Também será mostrado o princípio de funcionamento do acelerômetro e como este dispositivo pode ser utilizado para a monitoração de cães.

\subsection{A importância da movimentação canina}

A etologia é a parte da biologia que estuda os comportamentos animais, sendo que cada espécie possui características anatômicas específicas e um conjunto de padrões de comportamento. Desvios nesses padrões podem ser resultantes de alguma doença ou perturbação externa (SCHEIBE; GROMANN, 2006).

Algumas características físicas dos cães são específicas de cada raça, como o tamanho, pelagem e condições genéticas. A Federação Cinológica Internacional (FCI) reconhece hoje 353 raças de cães, reunidas em 10 grupos, que foram subdivididos conforme a estrutura física, porte e função destes animais. Devido a esta grande variedade, existem raças com menos de $20 \mathrm{~cm}$ como os Chihuahua, e raças com mais de $1 \mathrm{~m}$ de altura, como o Dinamarquês ou Dogue Alemão (LOPES; SILVA, 2012).

Os cães apresentam poucas diferenças entre os sexos, sendo os machos geralmente maiores e mais pesados. Possuem músculos fortes e sistema cardiovascular preparado para ações explosivas, como corridas e ataques. Na maior parte das raças, os membros anteriores são flexíveis e os posteriores possuem grande massa muscular, possibilitando executar saltos longos e corridas em altas velocidades (LOPES; SILVA, 2012).

A literatura sobre comportamento e bem-estar canino traça fortes correlações entre 
combinações de movimentos corporais e humores específicos, intenções ou desejos do animal (MILLS et al., 2010).

São apresentados a seguir alguns exemplos de comportamentos de cães explicados por GRISOLIO et al. (2017):

- Latidos: conforme a intensidade e duração podem indicar defesa territorial, demonstrar algum incomodo, ou significar algum pedido como por atenção, comida ou brinquedo.

- Rosnados: quando o cão rosna sem mostrar os dentes está verbalizando um desconforto com aquela situação, e nem sempre significa que pretende partir para a agressão.

- Gemidos, choros e uivos: podem indicar dor, incômodo, busca por cuidados/atenção ou até mesmo o início de uma comunicação com outros cães.

- Movimentação e posição da cauda: dependendo da posição e da intensidade do movimento pode ter diferentes significados:

- Movimentação insistente em conjunto com a parte posterior do corpo, pode indicar que o cão está feliz, agitado ou incomodado com algo ou alguém;

- Movimentação lenta, pode indicar que o cão está apreensivo;

- Se a cauda está caída pesadamente e parada, indica que o animal está calmo e, dificilmente, irá atacar;

- Se a cauda está empinada é indicativo de um estado de alerta, e entre as patas, de medo.

- Lambidas: as lambidas dos cães são uma forma de demonstrar curiosidade ou apaziguamento. Quando lambem o chão podem estar sentindo tédio; quando lambem as patas insistentemente, significa estresse; e quando lambem o ar, pode ser um indicativo de dor em algum local que o próprio animal não consegue definir.

- Abocanhar: a ação de abocanhar, sem a intenção de ferimento, é uma forma de brincadeira e comunicação comum entre cães, mas pode virar um problema se for persistente e o cão não responder ao comando de parar a brincadeira.

\subsection{Utilização do acelerômetro no estudo do movimento}

As principais vantagens da utilização do acelerômetro para o estudo dos movimentos é que este dispositivo coleta dados diretamente da movimentação, são precisos, resistentes e baratos, e permitem a monitoração a longo prazo, possibilitando identificar mudanças nos comportamentos. 
Para que essas vantagens sejam efetivas e o sistema de monitoração possa ser utilizado em um ambiente doméstico e não supervisionado, o mesmo deve ser confiável e robusto; deve ser leve e não obstrutivo, permitindo a execução das atividades naturais do cão; ter uma aparência discreta, não apresentando nenhum tipo de luz que possa incomodar ou chamar a atenção do cão; ser atóxico em contato com o pelo e, além disso, prover uma forma de comunicação para o envio dos dados coletados. Na próxima sessão será apresentado em detalhes o funcionamento do acelerômetro.

\subsubsection{Princípios básicos de funcionamento do acelerômetro}

O acelerômetro é um dispositivo projetado para medir a aceleração de um corpo quando submetido a uma força externa, sendo capaz de medir as acelerações dinâmica e estática. São consideradas acelerações dinâmicas as decorrentes da variação de velocidade em um deslocamento, vibrações e choques; e a aceleração estática é aquela decorrente da aceleração gravitacional. No mecanismo interno do acelerômetro ocorre a conversão de um vetor de aceleração em um sinal elétrico, que pode ser coletado e processado por sistemas eletrônicos (SILVA, 2013).

Figura 1 - Estrutura simplificada de um acelerômetro

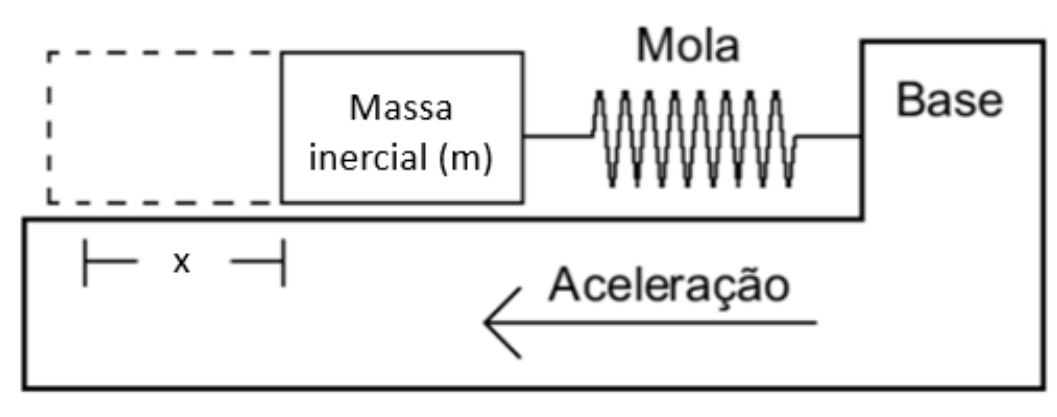

Fonte: Bruxel (2010).

A estrutura básica de um acelerômetro, como visto na Figura 1, é um sistema de massa e mola. Quando a massa inercial se desloca ela pressiona um conjunto de molas, causando uma compressão ou expansão. Aplicando a lei de Hooke é possível relacionar o deslocamento $x$ sofrido pela mola, cuja constante de compressão é $K$, com a força $F$, conforme descrito na equação 2.1:

$$
F=K * x
$$

Outro princípio físico envolvido é a segunda lei de Newton, que relaciona a aceleração $a$ sofrida pela massa $m$ como consequência de uma força $F$ aplicada sobre ela, conforme a equação 


\section{2 .}

$$
F=m * a
$$

Relacionando as equações 2.1 e 2.2, obtém-se a equação 2.3, onde medir a aceleração tornou-se uma questão de conhecer as constantes $k$ e $m$ e o deslocamento $x$ realizado pela massa inercial.

$$
a=\frac{k}{m} * x
$$

Os avanços na tecnologia MEMS (Micro-Electro-Mechanical Systems) possibilitaram a aplicação dos acelerômetros na monitoração de movimentos, já que atualmente encontramse comercialmente estes dispositivos em tamanho miniaturizado, com custo reduzido e com medições confiáveis. Os acelerômetros MEMs podem ser construídos de forma a serem do tipo piezoelétrico, piezoresistivo ou capacitivo, dependendo do efeito físico utilizado por cada um.

\subsubsection{Acelerômetro piezoelétrico}

Estes dispositivos baseiam-se no efeito piezoelétrico, que é a capacidade de alguns cristais gerarem cargas elétricas em reação a um esforço mecânico aplicado sobre ele. A Figura 2 ilustra o funcionamento de um acelerômetro piezoelétrico, composto por uma massa metálica sobre uma lamina de material piezoelétrico, dentro de uma caixa também metálica. Quando a caixa está em repouso, o material piezoelétrico sofre uma compressão devido ao peso da massa e resulta em uma tensão nos terminais (+ e -).

Quando a caixa é acelerada pra cima há um aumento da compressão no material piezoelétrico, resultando na elevação da tensão nos terminais de forma proporcional à aceleração. Analogamente, quando a caixa é acelerada para baixo, a compressão no material piezoelétrico diminui, bem como a tensão nos terminais (SEARA, 2019).

Figura 2 - Acelerômetro piezoelétrico

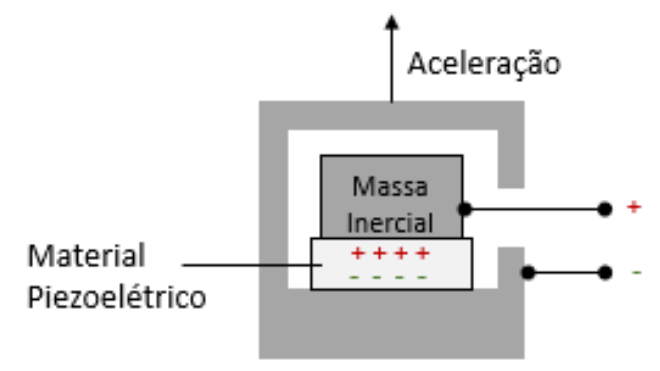

Fonte: SEARA (2019). 


\subsubsection{Acelerômetro piezoresistivo}

Estes acelerômetros utilizam molas com materiais piezoresistivos. Dessa forma, quando ocorre um movimento, há variação na resistência do material piezoresistivo, possibilitando a que a aceleração seja deduzida. Um ponto de atenção para o bom funcionamento deste tipo de acelerômetro é compensar a variação da resistência que ocorre devido à temperatura, pois esta variação pode ser maior que a provocada pelo deslizamento mecânico, e impedir a medição de pequenas acelerações (SILVA, 2013).

Uma forma de compensar a influência da temperatura é utilizar resistores formando um circuito ponte de Wheatstone, conforme visto na Figura 3. Dessa forma a temperatura afeta igualmente os quatro resistores e anula a influência na tensão da saída.

Figura 3 - Acelerômetro piezoresistivo

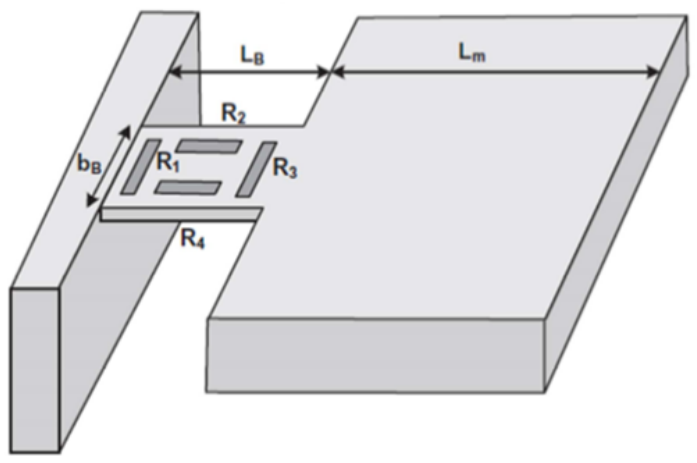

Fonte: Silva (2013).

\subsubsection{Acelerômetro capacitivo}

O acelerômetro capacitivo utiliza o princípio físico do capacitor, que consiste de duas placas metálicas separadas pelo ar, ou por algum outro material isolante, e que apresenta uma diferença de potencial entre as placas quando são aplicadas cargas elétricas de sinais opostos em cada uma delas. Mantendo as cargas elétricas contantes, pode-se variar a tensão nos terminais do capacitor a partir da variação da distancia entre as placas, sendo que quanto maior a distancia maior é a tensão nos terminais.

Um acelerômetro capacitivo pode ser formado por um sistema onde a distância entre as placas do capacitor depende da aceleração do conjunto, conforme a Figura 4. Com o sistema em repouso, a mola que segura a placa superior está distendida e a tensão é $V_{1}$. E quando o sistema é acelerado para cima, ocorre a compressão da mola e redução da distancia entre as placas do capacitor, resultando em uma tensão menor $V_{2}$. 
Figura 4 - Acelerômetro capacitivo
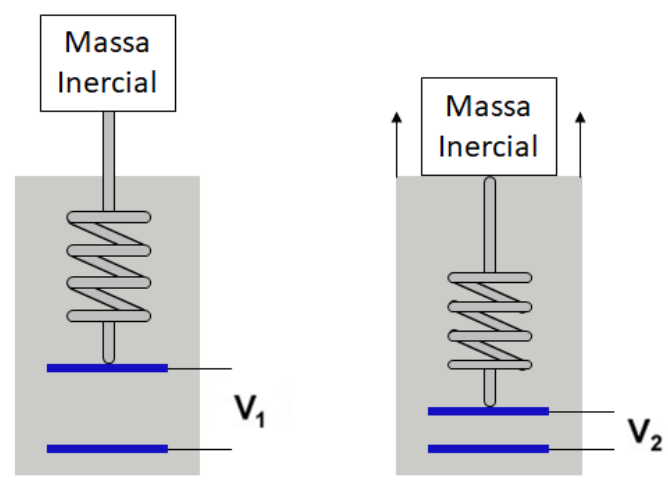

Fonte: SEARA (2019).

\subsection{Acelerômetro capacitivo utilizado neste trabalho}

O sensor utilizado neste trabalho é o ICM-20602, composto por um giroscópio e acelerômetro triaxias. Para prolongar a duração da bateria e otimizar o espaço da memória o giroscópio foi desativo e nenhum dado de rotação foi coletado.

O acelerômetro triaxial do ICM-20602 é do tipo capacitivo e utiliza massas de prova separadas para cada eixo, de modo que a aceleração ao longo de um determinado eixo induz o deslocamento na massa inercial correspondente e os sensores capacitivos detectam o deslocamento diferencialmente. Quando o dispositivo é colocado em uma superfície plana, medirá $0 \mathrm{~g}$ nos eixos X e Y e + 1g no eixo Z (INVENSENSE INC., 2016), como ilustra a Figura 5

Figura 5 - Eixos do acelerômetro

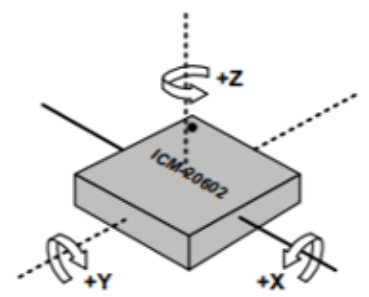

Fonte: InvenSense Inc. (2016).

Os movimentos reconhecidos pela monitoração utilizando acelerômetros acoplados ao corpo são limitados pela quantidade de sensores utilizados JUNIOR et al. (2020), e principalmente pelo seu posicionamento no corpo do cão. A utilização do acelerômetro acoplado na coleira é um bom posicionamento, pois a cabeça do cão desempenha um papel importante nas suas movimentações, seja diretamente em atividades como comer, beber ou latir, ou indiretamente por se movimentar com todo o corpo em atividades como andar e correr. 

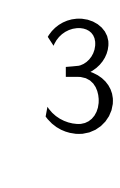

\section{DISPOSITIVOS COMERCIAIS PARA MONITORAÇÃO DE CÃES}

Neste capítulo serão apresentados alguns exemplos de dispositivos comerciais e suas principais funções relacionadas à monitoração de cães. Todos os dispositivos têm em comum a utilização do acelerômetro para a coleta contínua de dados, e alguns deles são equipados também com GPS para localização do cão em tempo real. Além disso, todos os produtos possuem um aplicativo para visualização das informações processadas.

É importante ressaltar que todos os dispositivos apresentados nesta sessão são desenvolvidos no exterior, principalmente nos Estados Unidos. No Brasil, existe apenas alguns dispositivos com GPS, mas sem o acelerômetro e a função de classificação dos movimentos dos cães.

\subsection{Whistle}

A Whistle utiliza um acelerômetro triaxial para estimar a quantidade de energia que o cão consumiu por minuto. E com base nesta estimativa são inferidas atividades como estar descansando, andando pela casa ou fazendo atividades mais vigorosas, como correr ou passear.

Para traduzir os valores coletados pelo acelerômetro nas atividades que o cachorro executou, são utilizados os chamados Pontos de Atividade Whistle (do inglês Whistle Activity Points), uma métrica desenvolvida pelos pesquisadores da Whistle que considera os sinais obtidos pelo acelerômetro numa frequência de $50 \mathrm{~Hz}$, sendo que quanto maior a movimentação do sensor, maior é o Ponto de Atividade. Utilizando os dados do acelerômetro o dispositivo ainda consegue identificar o nível de coceira e calorias gastas no dia pelo cachorro.

O dispositivo Whistle também é equipado com GPS e por isso apresenta a localização do cão em tempo real, permitindo inclusive o envio de notificações no aplicativo caso a cão saia de uma determinada área de segurança. Outro diferencial deste produto é a possibilidade de contatar 
atendimento veterinário pelo aplicativo (WHISTLE, 2020).

A empresa Whistle possui o projeto "Pet Insight" cujo objetivo é coletar dados de comportamento dos cães, através do dispositivo, e disponibilizar estes dados para pesquisadores e profissionais veterinários que desejam conduzir pesquisas relacionadas ao bem estar animal e clínica veterinária. Mais informações sobre este projeto podem ser obtidas em: <www.petinsight. $\mathrm{com} / \mathrm{s}$.

Figura 6 - Dispositivo Whistle Go

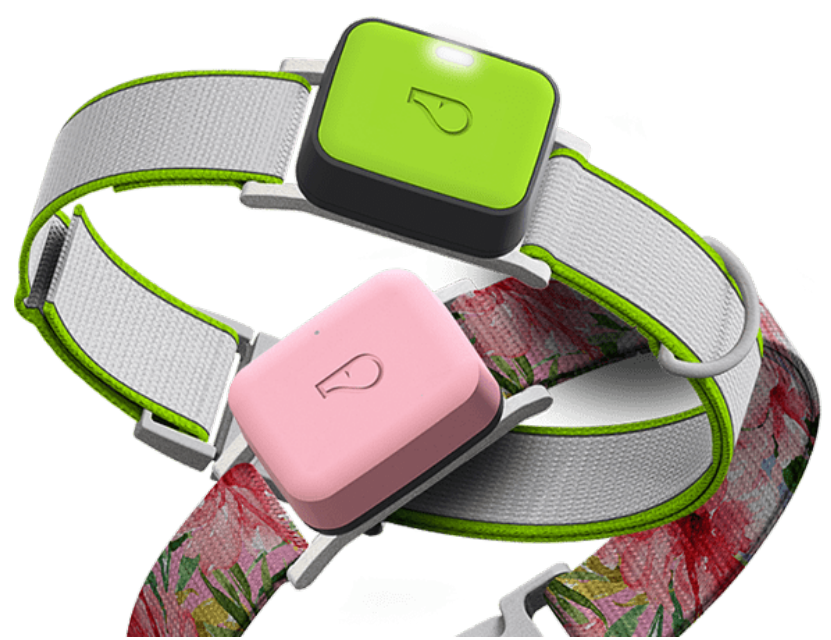

Fonte: Whistle (2020).

\subsection{FitBark}

O FitBark possui duas versões de dispositivo: o Fitbark 2, que apresenta as funcionalidades de monitoramento de atividades, monitoramento do sono, cálculo de distância percorrida, calorias queimadas e monitoramento da frequência cardíaca para reconhecimento de situações de alta ansiedade; e o Fitbark GPS, que possui as mesmas funcionalidades do Fitbark 2 e mais o sensor de GPS, sendo esta versão comercializada apenas nos Estados Unidos.

De modo semelhante ao Whistle, o Fitbark também utiliza um sistema de pontos para converter os dados do acelerômetro triaxial em "BarkPoints". Baseado na idade e no porte do cão, o aplicativo Fitbark recomenda uma meta diária de BarkPoints que devem ser atingidos para que o cão tenha uma rotina saudável (FITBARK, 2020).

A empresa FitBark possui uma base de dados com mais de 300 raças de cães, espalhados por 140 países. Alguns estudos baseados nestes dados são apresentados em <www.fitbark.com/ explore/>. 
Figura 7 - FitBark Dog Activity Monitor

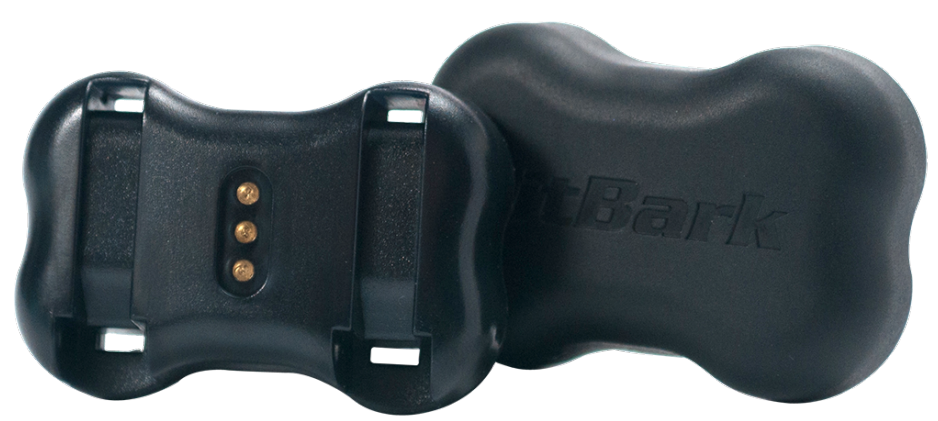

Fonte: FitBark (2020).

\subsection{Link}

O dispositivo Link utiliza os dados do acelerômetro para classificar os movimentos do cão em atividades moderadas e intensas. Esses dados são relacionados com as informações de idade e raça para indicar uma meta diária, em minutos, da quantidade de movimentos intensos recomendados para o cão.

O Link também apresenta as funcionalidades de localização em tempo real e alerta para quando cão sai de uma área de segurança. Apresenta ainda um sensor de temperatura que gera um alerta no aplicativo quando o cão encontra-se em um ambiente que pode ser muito frio ou muito quente para ele (LINK, 2020).

Figura 8 - LINK AKC Smart Dog Collar

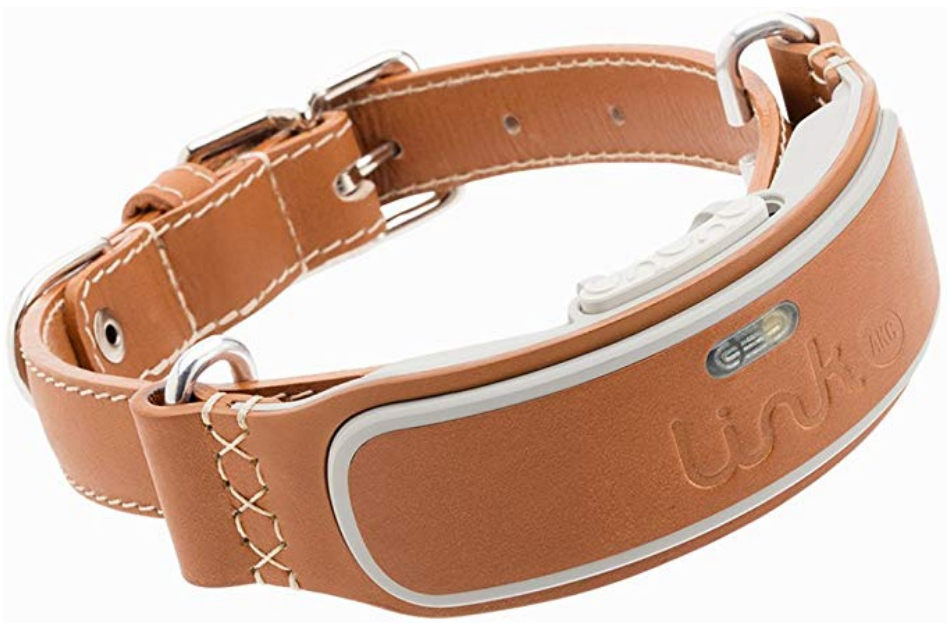

Fonte: Link (2020). 


\subsection{PetPace}

Uma particularidade do dispositivo PetPace em relação aos outros apresentados nesta sessão, é uma quantidade mais variada de coleta de dados de saúde dos cães, pois além de apresentar o acelerômetro para monitoração do nível de atividade e o termômetro para monitoração da temperatura ambiente, ainda apresenta as seguintes medições:

- Pulso, ou batimento cardíaco, que é a medida do número de vezes que o coração bate por minuto,

- Taxa de respiração, que corresponde ao número de respirações (troca de gases entre o corpo e o ambiente) por minuto, e

- Variabilidade da Frequência Cardíaca (VFC), que é uma análise estatística das pequenas variações nos intervalos de tempo entre os batimentos cardíacos.

O Petpace apresenta ainda um serviço de monitoramento que é voltado para 3 categorias de cães: saudáveis, idosos e animais que apresentam alguma doença. O monitoramento 24 horas por dia faz com que caso seja detectado alguma alteração nos sinais vitais do cão, sejam enviados alertas tanto para o tutor quanto para o veterinário que atende o animal.(PETPACE, 2020).

\section{Figura 9 - PetPace Smart-Sensing Collar}

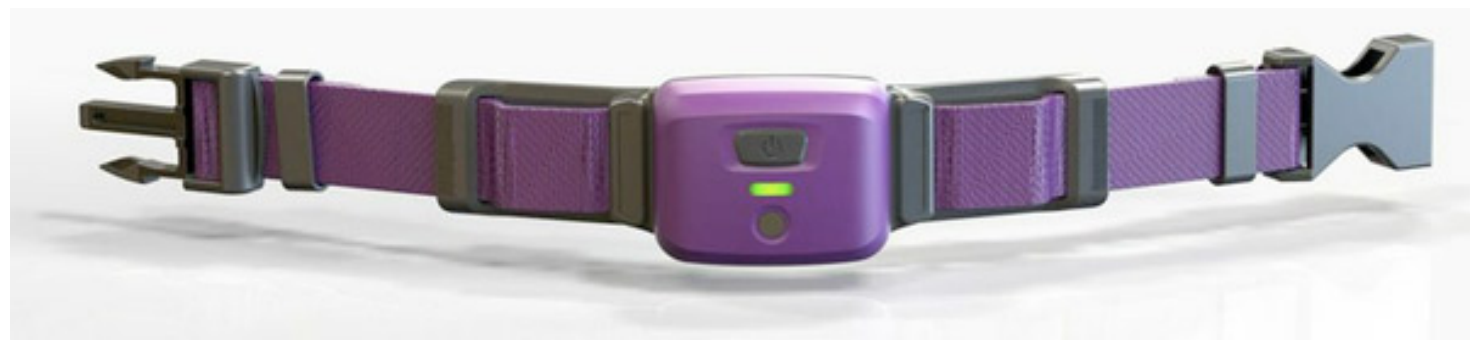

Fonte: PetPace (2020). 
A Rede Neural Convolucional estabeleceu-se como uma técnica poderosa para o reconhecimento de movimentos coletados por sensores, pois as operações de convolução e pooling aplicadas às séries temporais são capazes de identificar a dependência local ao longo dos domínios temporais e espaciais.

Este capítulo tem como objetivo apresentar os fundamentos teóricos das Redes Neurais Convolucionais, explicando os métodos utilizados por esta técnica e os benefícios de sua aplicação. E para iniciar será apresentada uma breve introdução sobre as Redes Neurais Artificiais.

\subsection{Redes Neurais Artificiais}

As Redes Neurais Artificiais (RNA) são estruturas de processamento de informações paralela e distribuída inspiradas em redes neurais biológicas, que originaram no trabalho de McCulloch e Pitts (1943). As unidades básicas das RNAs são os neurônios artificiais, que podem ser representados graficamente como na Figura 10.

Os elementos dos neurônios artificiais possuem as seguintes funções:

- Sinais de entrada $\left(x_{m}\right)$ : são os dados que servirão como base para o treinamento da rede.

- Pesos sinápticos $\left(w_{k p}\right)$ : cada dado da entrada é associado a um peso diferente, o que determina a influência da entrada para o resultado final.

- Limiar de ativação ou bias $\left(b_{k}\right)$ : é um deslocamento linear que permite melhor adaptação da rede.

- Somatório: responsável pela combinação linear de todas as entradas. 
Figura 10 - Neurônio artificial

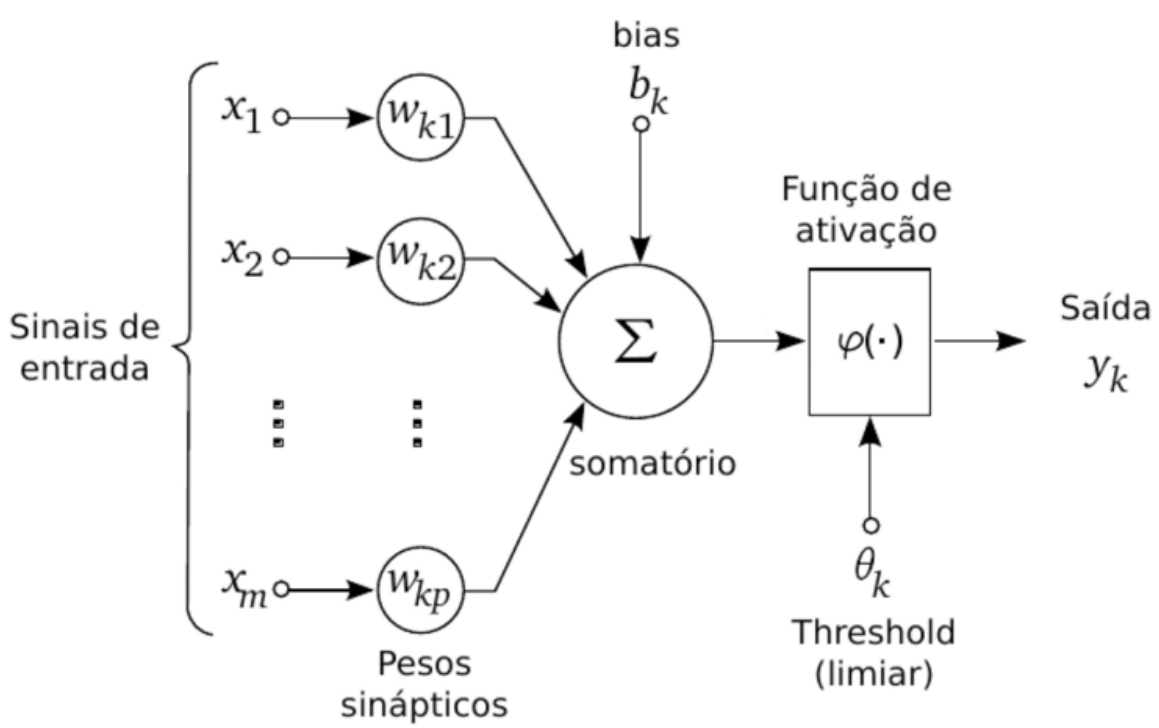

Fonte: Haykin (2007).

- Função de ativação: $(\varphi()$.$) : aplica uma não-linearidade ao neurônio e determina a forma$ como ele será ativado, também é responsável por limitar a saída do neurônio a um valor finito e normalizado (exemplos: $[0,1]$ ou $[-1,1]$ ).

- Saída $\left(y_{k}\right)$ : é o resultado estimado pelo neurônio.

O neurônio artificial pode ser expresso matematicamente como descrito na equação 4.1

$$
y_{k}=\varphi\left(\sum_{i=0}^{m} x_{i} w_{k i}+b_{k}\right)
$$

As funções de ativação mais utilizadas são: sigmoidal logística, tangente hiperbólica e unidade linear retificada (do inglês: Rectified Linear Unit, abreviada por ReLU). Essas funções são representadas da Figura 11.

Figura 11 - Exemplos de funções de ativação
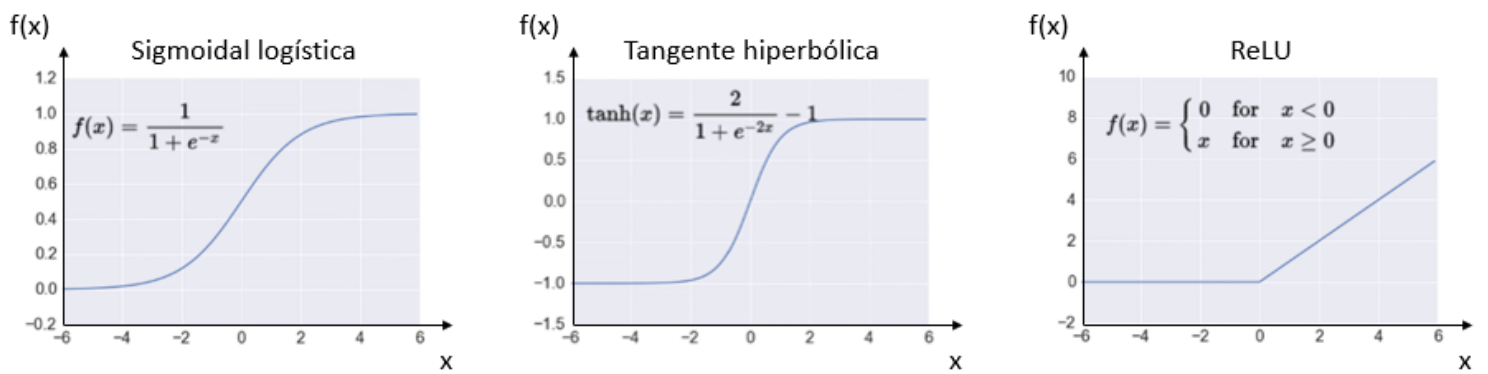

Fonte: Maalej e Kherallah (2020). 


\subsubsection{Rede Neural Multicamadas}

Uma rede neural de camada única é chamada Perceptron, e ela funciona como um classificador linear binário. Para resolver os problemas não lineares foi desenvolvida uma rede mais robusta chamada Rede Neural Multicamadas (MLNN), do inglês Multi-layer Neural Network.

A MLNN é uma generalização do Perceptron, na qual conjuntos de neurônios artificiais são distribuídos em camadas. A primeira camada é a de entrada, cuja função é receber os dados e transmiti-los para a camada seguinte. As camadas intermediárias são chamadas de camadas ocultas, sendo responsáveis pelo processamento das informações. Por último encontra-se a camada de saída, que tem como objetivo apresentar a resposta da rede ao problema em questão, que pode ser a identificação da classe a qual pertence a entrada ou um resultado de processamento em valor contínuo, a Figura 12 ilustra esta estrutura multicamadas.

Figura 12 - Rede Neural Multicamadas

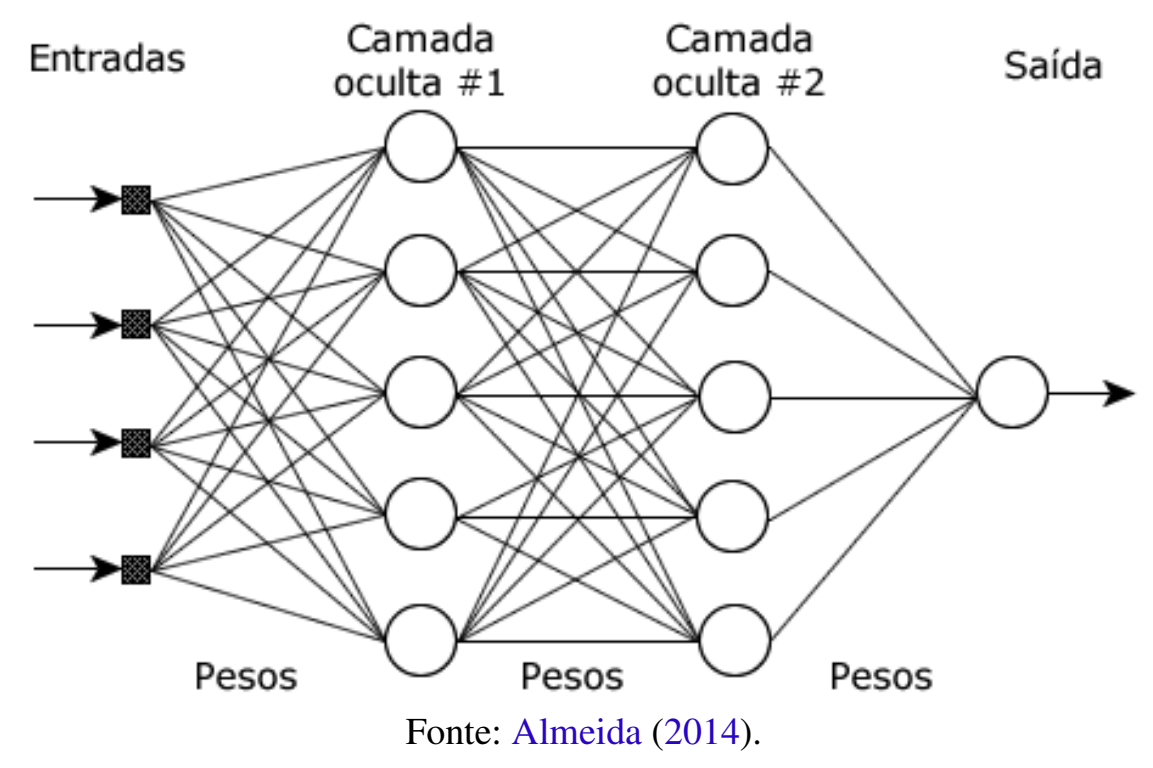

O treinamento da rede neural artificial efetua o ajuste dos parâmetros livres, pesos sinápticos e viés ("bias") de cada neurônio, para que a função desconhecida, da qual se tem apenas o mapeamento entrada-saída dado pelo conjunto de dados de treinamento, seja aproximada pela rede. $\mathrm{O}$ algoritmo utilizado para o treinamento de uma rede neural de topologia MLNN é o "Error back propagation", que como o nome sugere, propaga o sinal de erro de forma reversa ao fluxo normal da rede, ou seja, o erro calculado entre a saída esperada e a apresentada em cada neurônio de saída é propagado para a camada anterior, e assim sucessivamente até a camada de entrada. Na propagação do erro, os parâmetros dos neurônios da camada corrente são individualmente atualizados por um valor proporcional ao sinal de entrada e ao gradiente local, sendo este último correspondente ao gradiente descendente do erro em função dos pesos. Este processo interativo é repetido até que o erro seja minimizado. 


\subsubsection{Redes Neurais Convolucionais}

As Redes Neurais Convolucionais (CNN), do inglês Convolutional Neural Network, surgiram a partir do estudo do córtex visual do cérebro de gatos elaborado por Hubel e Wiesel (1962). Neste trabalho os autores demostraram que muitos neurônios no córtex visual têm um pequeno campo receptivo local, o que significa que eles reagem apenas a estímulos visuais localizados em uma região limitada do campo visual. Na Figura 13 é ilustrado este acontecimento, onde cada neurônio possui um campo receptivo diferente e reconhece um padrão específico.

Figura 13 - Campos receptivos locais no córtex visual

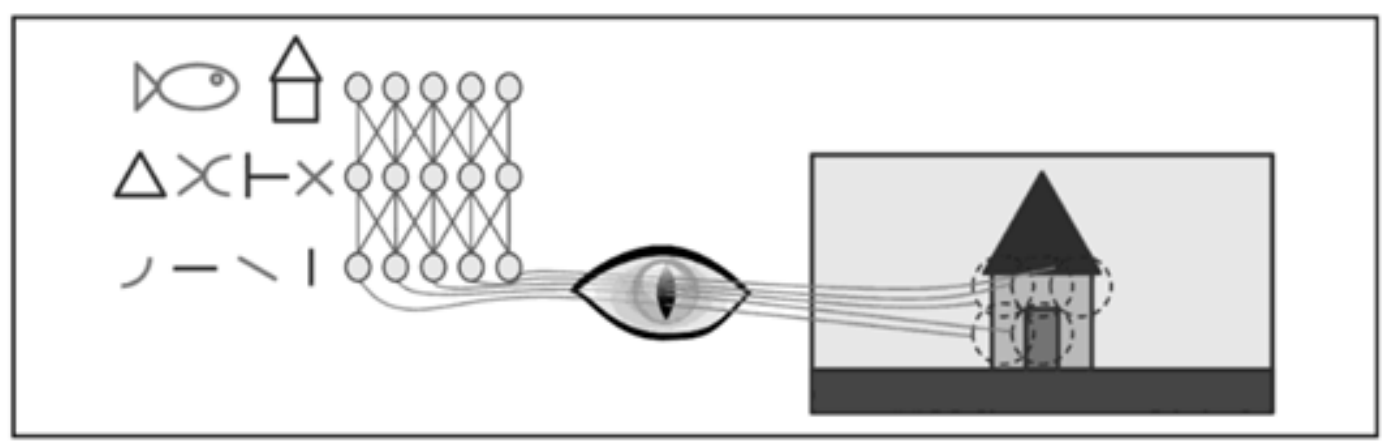

Fonte: GERON (2009).

Os campos receptivos de diferentes neurônios podem se sobrepor e, juntos, formam todo o campo visual. Os autores também mostraram que alguns neurônios reagem apenas a imagens nas linhas horizontais, enquanto outros reagem apenas a linhas com diferentes orientações. Alguns neurônios tem campos receptivos maiores e reagem a padrões mais complexos, que são combinações dos padrões de nível inferior. Essas observações levaram a concluir que os neurônios de nível superior são baseados nas saídas dos neurônios de nível inferior, fazendo com que esta arquitetura seja capaz de detectar todos os tipos de padrões complexos em qualquer área do campo visual (GERON, 2009). Estes estudos do córtex visual foram a base para as pesquisas em CNNs.

A CNN pode ser considerada uma variação da MLNN, mas em vez de usar camadas ocultas totalmente conectadas, a arquitetura da CNN se baseia na alternação de camadas de convolução e camadas de pooling. Cada camada possui um conjunto de filtros, também conhecido como kernel, que serão responsáveis por extrair características locais (local features) de uma entrada (VARGAS; CARVALHO; VASCONCELOS, 2016). Por último, a rede possui uma camada totalmente conectada, que conecta todos os neurônios da camada anterior a ela aos neurônios de saída, esta camada é responsável pelo processo de classificação, conforme ilustra a Figura 14. 
Figura 14 - Exemplo de arquitetura de uma CNN

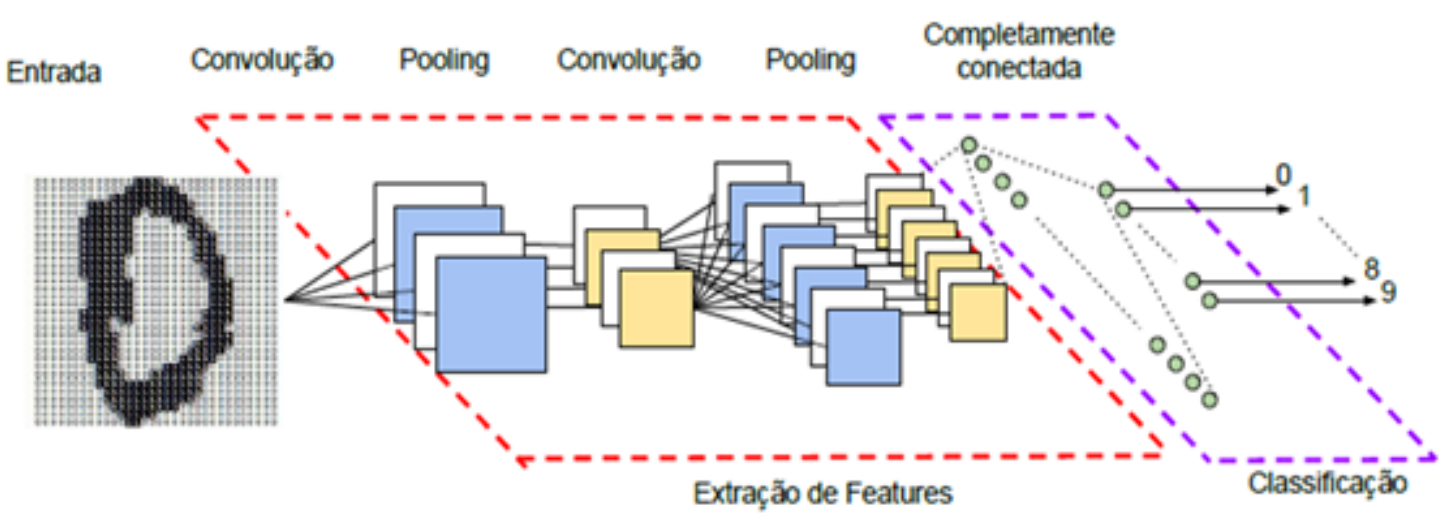

Fonte: VARGAS, CARVALHO e VASCONCELOS (2016).

\subsubsection{Camada Convolucional}

As camadas convolucionais utilizam filtros não lineares para percorrer sequencialmente os dados de entrada (ou da camada anterior). Para cada sequência percorrida sobre a entrada, é calculado o produto entre cada elemento do filtro ou Kernel e o elemento de entrada que ele sobrepõe, e os resultados são somados para obter a saída correspondente aquela localização. O resultado final deste procedimento é denominado mapa de características. A Figura 15 exemplifica a operação de convolução, onde a entrada é representada por uma matriz de tamanho $5 \times 5$ e o filtro representado por uma matriz de tamanho $3 \times 3$.

Figura 15 - Operação de Convolução

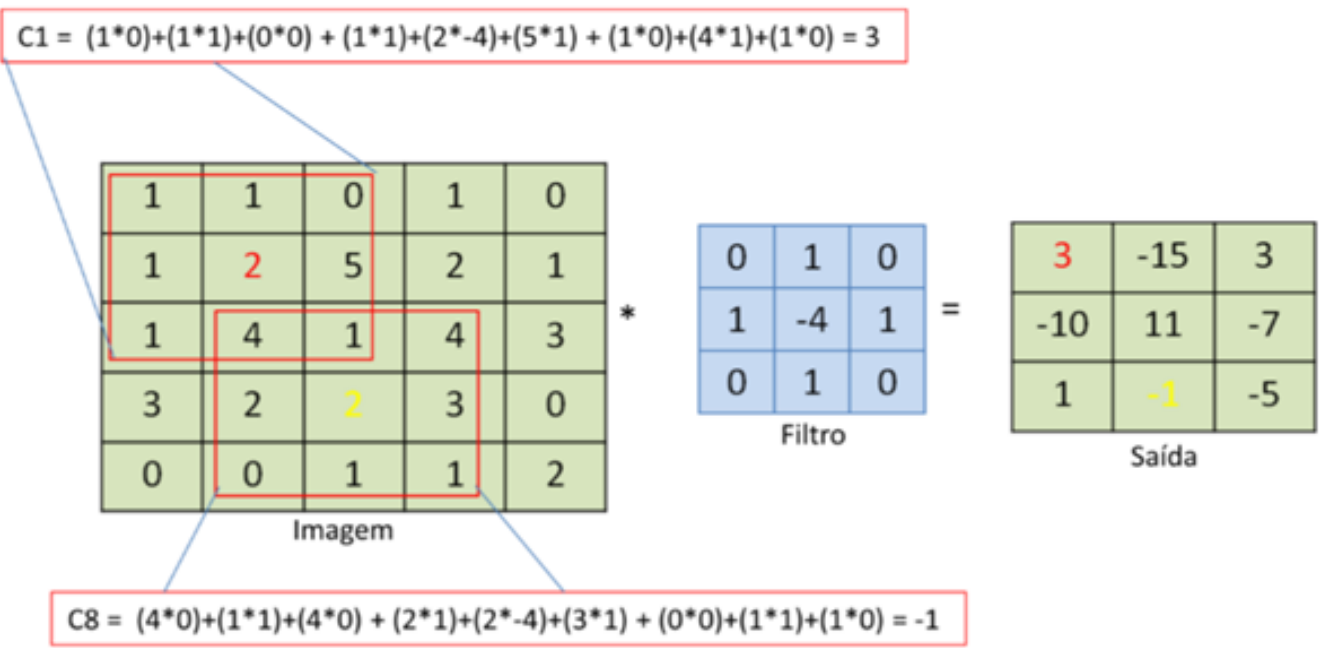

Fonte: FARIA (2018).

Durante o processo de treinamento, os filtros são ajustados automaticamente para que sejam ativados na presença de determinadas características, como orientação de bordas ou 
manchas de cores em imagens (KARPATHY, 2017). Dessa forma, diferentes filtros podem produzir diferentes mapas de características para um mesmo tipo de dado.

Existem algumas características particulares da CNN que a diferem de modelos de redes neurais que apresentam arquiteturas rasa, são elas: conectividades esparsa, campos receptivos locais e compartilhamento de parâmetros. Estas características permitem às CNNs armazenarem menos parâmetros, o que reduz os requisitos de memória do modelo e melhora a sua eficiência estatística (GOODFELLOW; BENGIO; COURVILLE, 2016). Estas características são detalhadas a seguir.

- Conectividade esparsa: o filtro utilizado no processo de convolução apresenta dimensões muito menores do que a matriz de entrada, isso permite uma correlação espacial, caracterizando a conectividade esparsa. No exemplo da Figura 16 é possível observar a conectividade esparsa, onde utilizando um filtro de tamanho 3, por exemplo, tem-se que apenas as unidades N2, N3 e N4 da camada de saída são afetadas pela entrada x3. Para comparação é ilustrado, na mesma figura, o caso da conectividade global utilizada pela arquitetura MLNN, onde todas as unidades da camada de saída são afetadas por todas as entradas.

Figura 16 - Conectividade esparsa da rede CNN e conectividade global da rede MLNN

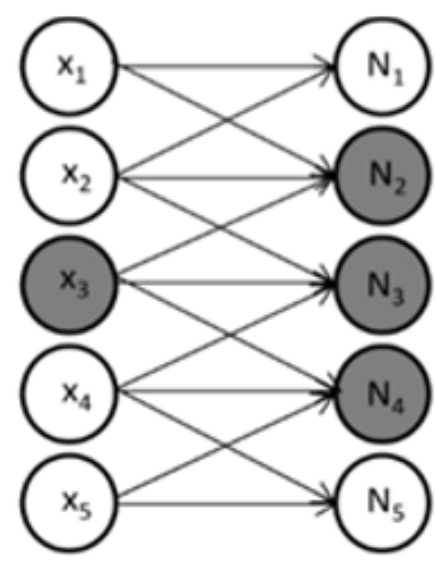

Conectividade Esparsa

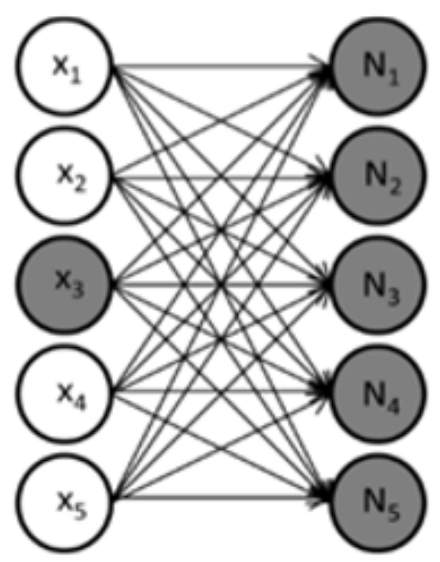

Conectividade Global

Fonte: FARIA (2018).

- Campos receptivos locais: são caracterizados pelas regiões na matriz de entrada por onde o filtro se desloca, sendo que a operação de convolução realizada a cada deslocamento corresponde a um novo neurônio na camada escondida. Este procedimento está representado na Figura 17, onde os neurônios destacados em preto em (a) representam o campo receptivo local do neurônio N1, e o mesmo acontece em (b) para o neurônio N2. 
Figura 17 - Campos receptivos locais da CNN

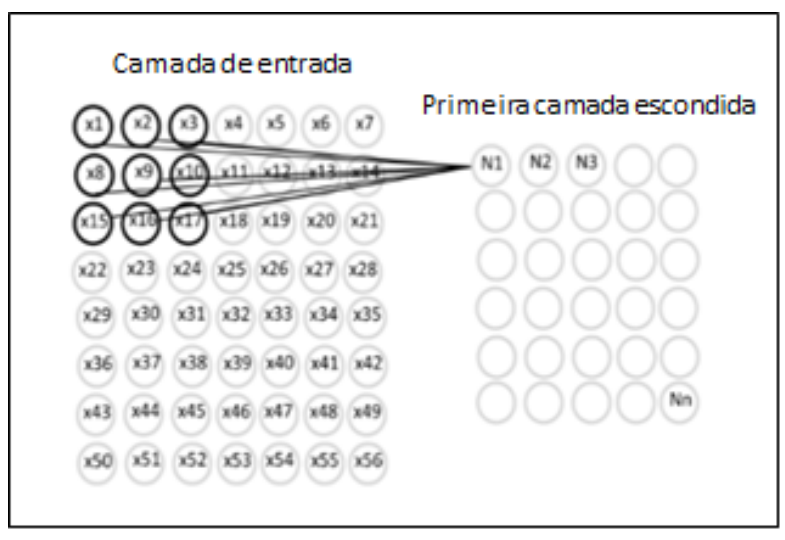

(a) Camporeceptivo local de N1

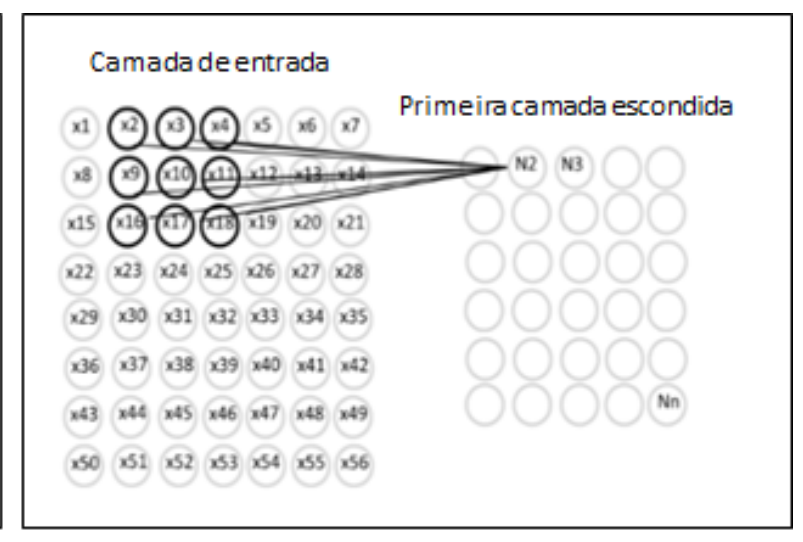

(b) Campo receptivo local de N2

Fonte: FARIA (2018).

- Compartilhamento de parâmetros: os mesmos filtros são aplicados por toda a matriz de entrada. Isto faz com que os padrões que ocorrem com frequência possam ser aprendidos, estejam eles em qualquer parte da matriz de entrada (Hafemann et al., 2015). No exemplo da Figura 18 há 3 mapas de características, cada mapa é definido por um filtro com compartilhamento de parâmetros, como resultado essa rede é capaz de detectar 3 diferentes tipos de padrões, podendo esses padrões serem detectados por toda a matriz de entrada (NIELSEN, 2016).

Figura $18-\mathrm{CNN}$ com três mapas de características

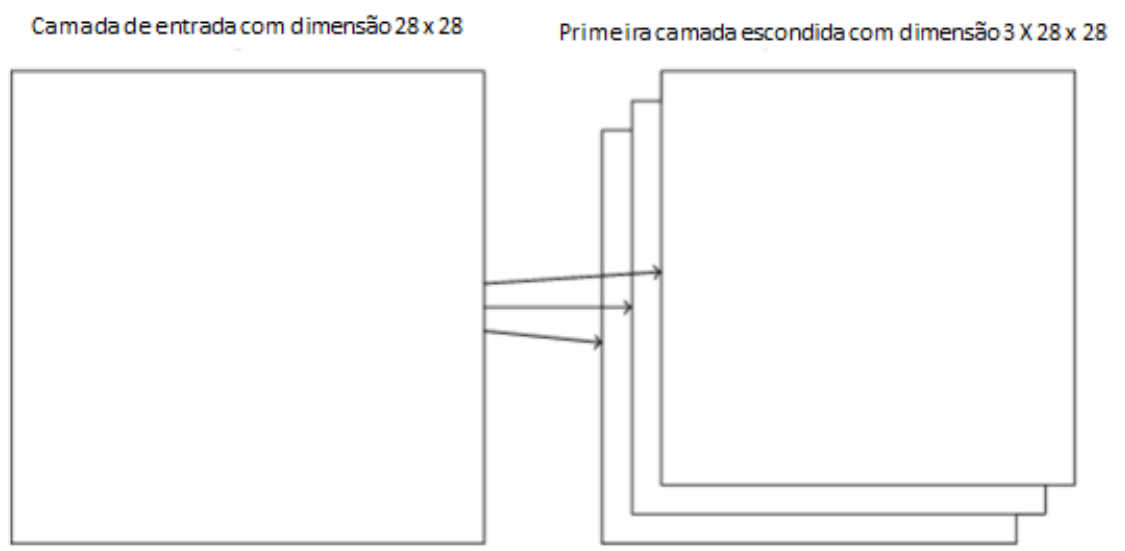

Fonte: Elaborada pelo autor.

A Figura 19 mostra como cada camada convolucional varia a largura (width) e altura (height) conforme os dados percorrem a CNN. Esta variação ocorre com a mudança de dois parâmetros na operação de convolução: o passo dos filtros (stride) e o preenchimento na camada que sofrerá a convolução (padding) (MIYAZAKI, 2017). A profundidade (depth) da saída de 
uma convolução é igual a quantidade de filtros aplicados, sendo que quanto mais profundas são as camadas das convoluções, mais detalhados são os traços identificados.

Figura 19 - Camadas convolucionais

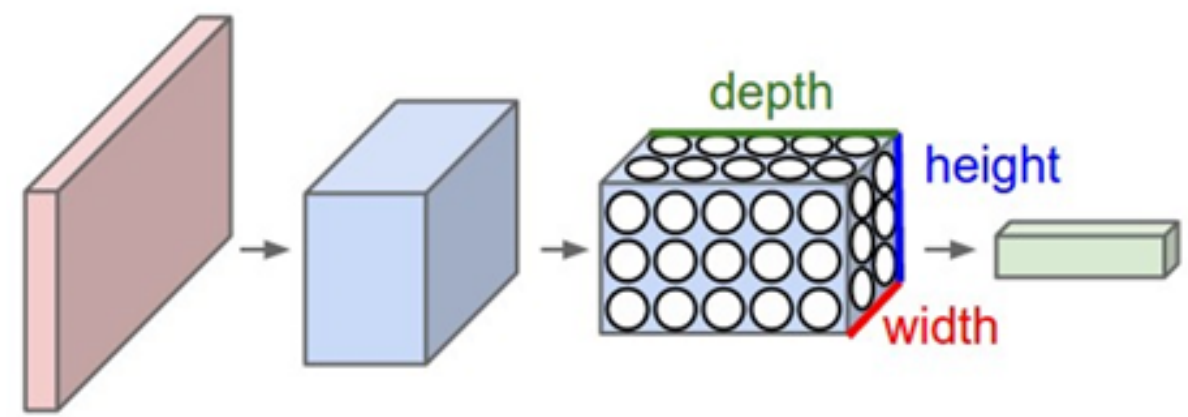

Fonte: Karpathy (2017).

Os filtros da operação de convolução deslizam por toda a matriz de forma sequencial, o tamanho desse deslizamento é chamado de stride. Durante o deslizamento dos filtros, uma forma de lidar com as bordas é o same padding, onde as fronteiras da matriz são preenchidas com 0 de modo a controlar a altura e largura na camada de saída, este preenchimento é ilustrado na Figura 20. Outra abordagem é o valid padding, onde as bordas do filtro não ultrapassam as bordas da matriz, e ocorre a redução na largura e altura das próximas camadas da rede.

Figura 20 - Exemplo de same padding

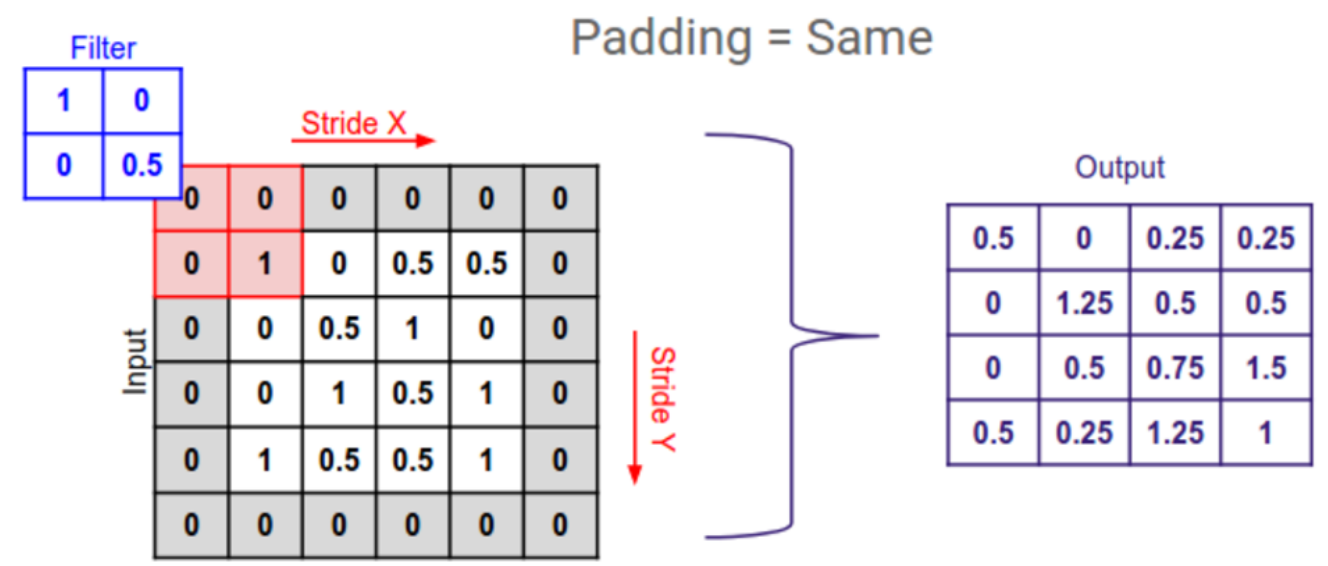

Fonte: Alves (2018).

\subsubsection{Função de ativação}

Os resultados obtidos ao efetuar o processo de convolução em uma matriz de entrada juntamente com a adição de um termo de bias são utilizados como entrada para uma função de ativação. A função de ativação serve para trazer a não-linearidade ao sistema, para que a rede 
consiga aprender qualquer tipo de funcionalidade. A melhor função de ativação a ser utilizada em modelos de RNAs é a função ReLu, entretanto funções de ativação tangente hiperbólica e sigmoide, ilustradas na Figura 11 também podem ser utilizadas tanto em modelos de rede MLNN como em modelos de rede $\mathrm{CNN}$.

\subsubsection{Camada de Pooling}

A camada de Pooling é geralmente utilizada após uma camada convolucional, e é responsável por reduzir a dimensão da camada anterior, diminuindo o custo computacional e evitando overfiting, isso ocorre através da seleção das informações mais significativas encontradas nas camadas convolucionais. O método mais utilizado é o Max Pooling, que consiste em delimitar regiões e selecionar o valor máximo de cada uma delas, conforme ilustra a figura Figura 21. Este processo faz com que a rede crie resistência a pequenas variações e distorções locais (ARAÚJO; CARNEIRO; SILVA, 2017).

Figura 21 - Exemplo de max pooling com filtro $2 \times 2$ e stride igual a 2

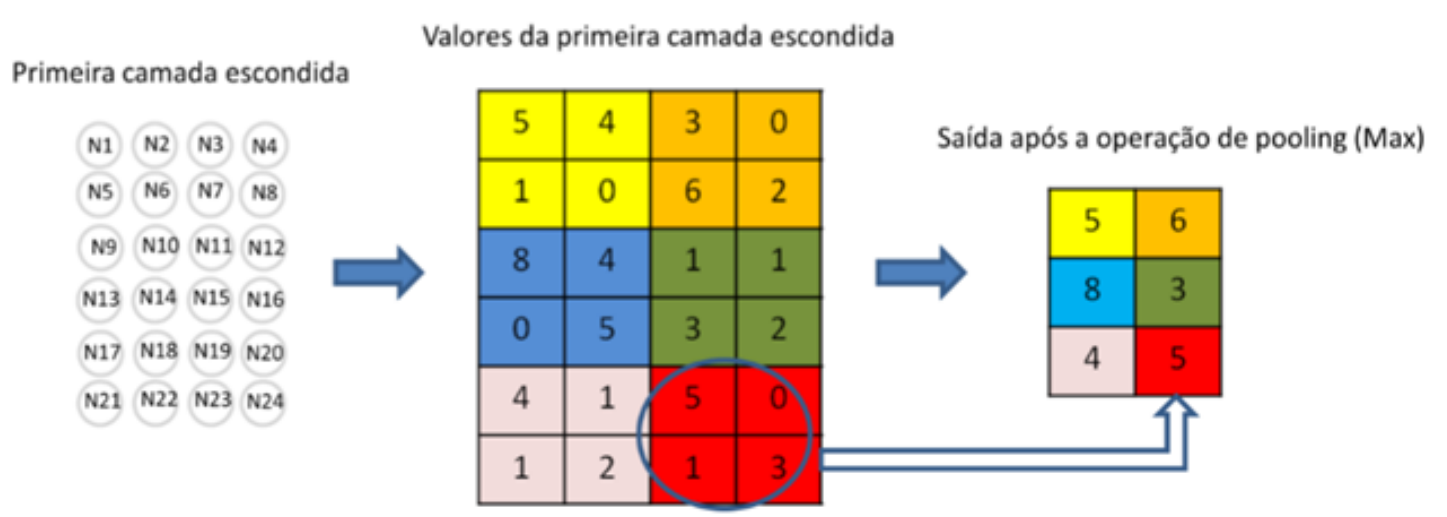

Fonte: FARIA (2018).

\subsubsection{Dropout}

Devido à presença da conectividade local, as CNNs possuem comprovadamente menos conexões e parâmetros quando comparadas com as redes MLNNs tradicionais. Entretanto as aplicações que fazem uso deste tipo de arquitetura podem chegar a apresentar milhares de camadas de processamento, aumentando substancialmente a quantidade de parâmetros da rede. Consequentemente, esta maior complexidade da $\mathrm{CNN}$ pode apresentar um problema conhecido como sobreajuste ou overfitting, ou seja, quando o modelo se ajusta muito bem aos dados apresentados durante o processo de treinamento, mas se mostra ineficiente na previsão dos dados de teste (FARIA, 2018).

O dropout é uma técnica de regularização utilizada para tratar o problema do overfiting, ele consiste em remover aleatoriamente a cada iteração de treinamento uma determinada porcentagem dos neurônios de uma camada, os adicionando novamente na iteração seguinte. $\mathrm{O}$ 
dropout também permite que a rede aprenda atributos mais robustos, pois um neurônio não pode depender da presença específica de outros neurônios(ARAÚJO; CARNEIRO; SILVA, 2017). A Figura 22 ilustra na direita uma rede neural sem dropout, com todos os neurônios ativos. Já a rede da esquerda apresenta um neurônio da segunda camada aleatoriamente desligado, caracterizando o dropout (EBERMAM; KROHLING, 2018).

Figura 22 - Exemplo de rede sem e com dropout

sem dropout

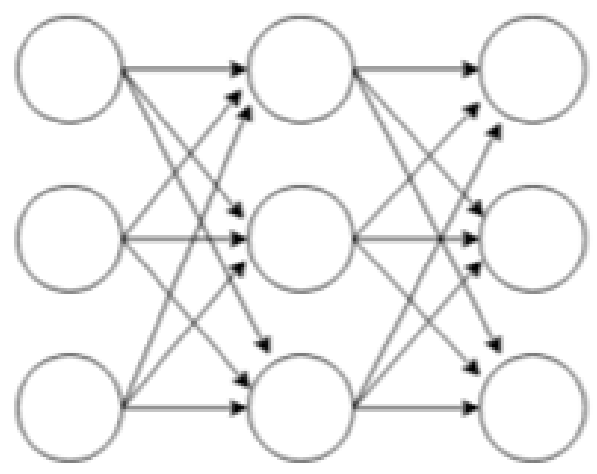

com dropout

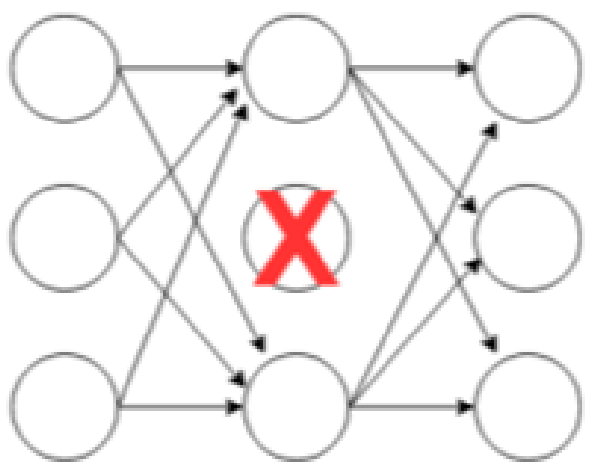

Fonte: Ebermam e Krohling (2018).

\subsubsection{Camada totalmente conectada}

As redes CNNs apresentam uma ou mais camadas totalmente conectadas (fully connected). O objetivo desta camada é usar as características geradas a partir das camadas de convolução e pooling para fazer a classificação dos dados de entrada em várias classes baseadas em um conjunto de treinamento.

Na Figura 23 é possível observar 10 mapas de características de tamanho 4 x 4 colocados de forma linear para formar a primeira camada totalmente conectada (camada flatten composta por 160 neurônios). Essas entradas alimentam a segunda camada totalmente conectada (camada escondida composta por 7 neurônios). No final da cadeia de processamento da camada totalmente conectada pode ser visualizada a camada de saída (composta por 3 neurônios) que correspondem às classes do modelo. Nesta ultima camada é utilizada a função de ativação softmax descrita na equação 3.16, onde Y corresponde ao vetor de saída do classificador. Esta função transforma um vetor de pontuação arbitrária de valores reais em um vetor de probabilidades entre zero e um e que juntos somam 1. E a resposta final do classificador pode ser obtida através da seleção do item que possui a maior probabilidade. 
Figura 23 - Camadas totalmente conectada composta por 3 camadas (flatten, escondida e saída)

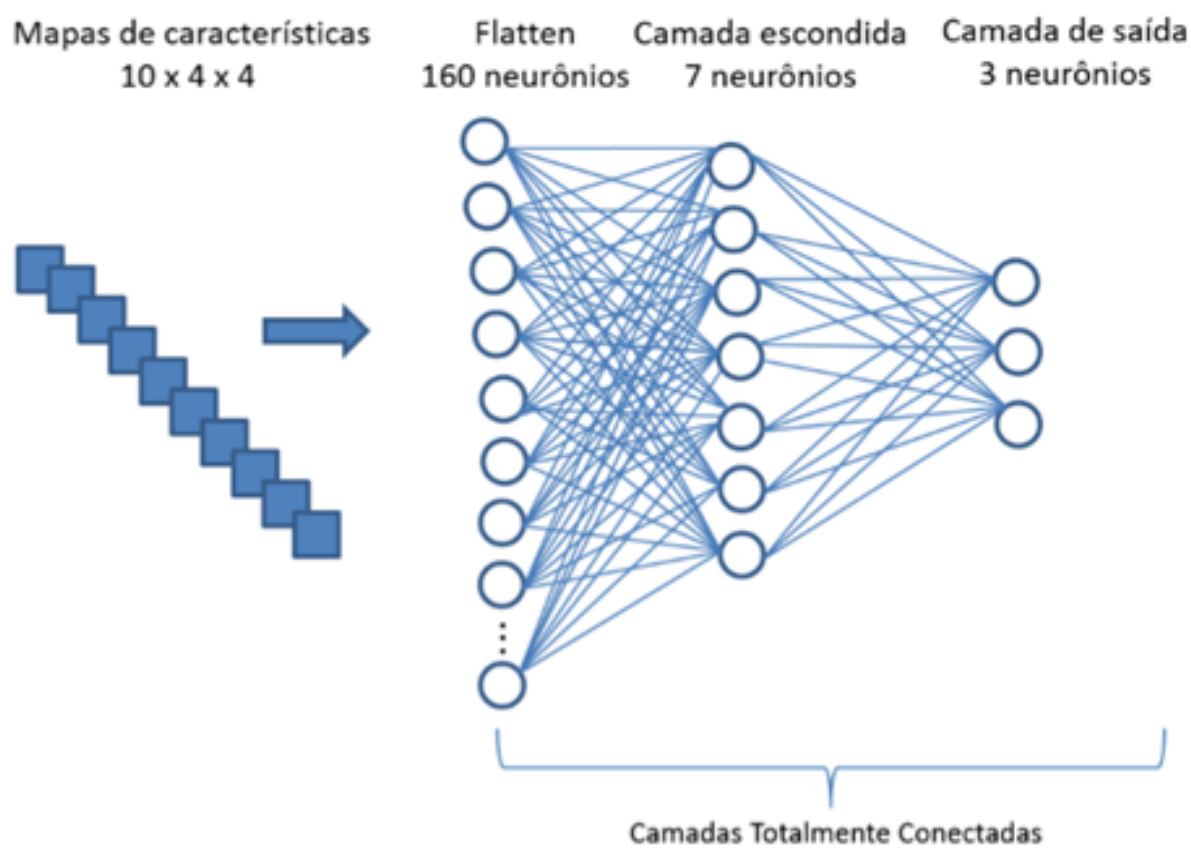

Fonte: FARIA (2018).

\subsubsection{Redes Neurais Recorrentes}

As Redes Neurais Recorrentes (RNN), do Inglês Recurrent Neural Networks, são especializadas em reconhecer padrões de séries temporais. Elas são chamadas de recorrentes porque possuem conexões de retroalimentação, onde um neurônio produz uma saída que é enviada de volta para ele mesmo, conforme ilustra a Figura 24 (à esquerda). Um forma de pensar sobre esta operação é que as RNNs possuem uma "memória"com informações do que já foi calculado, pois a cada intervalo de tempo t o neurônio recebe as entradas $\mathrm{x}(\mathrm{t})$ e também sua própria saída do intervalo de tempo anterior, $\mathrm{y}(\mathrm{t}-1)$ (GERON, 2009). A apresentação dessa rede representada ao longo do tempo é chamado desenrolando a rede ao longo do tempo, visto à direita na Figura 24.

Os neurônios recorrentes possuem um conjunto de pesos para as entradas $X_{(t)}$, chamado $W_{x}$, e outro conjunto para as saídas do intervalo de tempo anterior, $Y_{(t-1)}$, chamado $W_{y}$. Sendo b o vetor de polarização e $\varphi($.$) a função de ativação, a saída da camada recorrente pode então ser$ calculada como mostra a 4.2:

$$
Y_{(t)}=\varphi\left(X_{(t)} \cdot W_{x}+Y_{(t-1)} \cdot W_{y}+b\right)
$$

As RNNs são capazes de aprender as dependências de tempos para períodos curtos, mas para problemas relacionados a dependências de longo prazo nos dados é indicado a utilização da Memória Longa de Curto prazo (LSTM), do inglês Long Short Term Memory, apresentada na próxima sessão. 
Figura 24 - Um neurônio recorrente (à esquerda), desenrolado através do tempo (à direita)
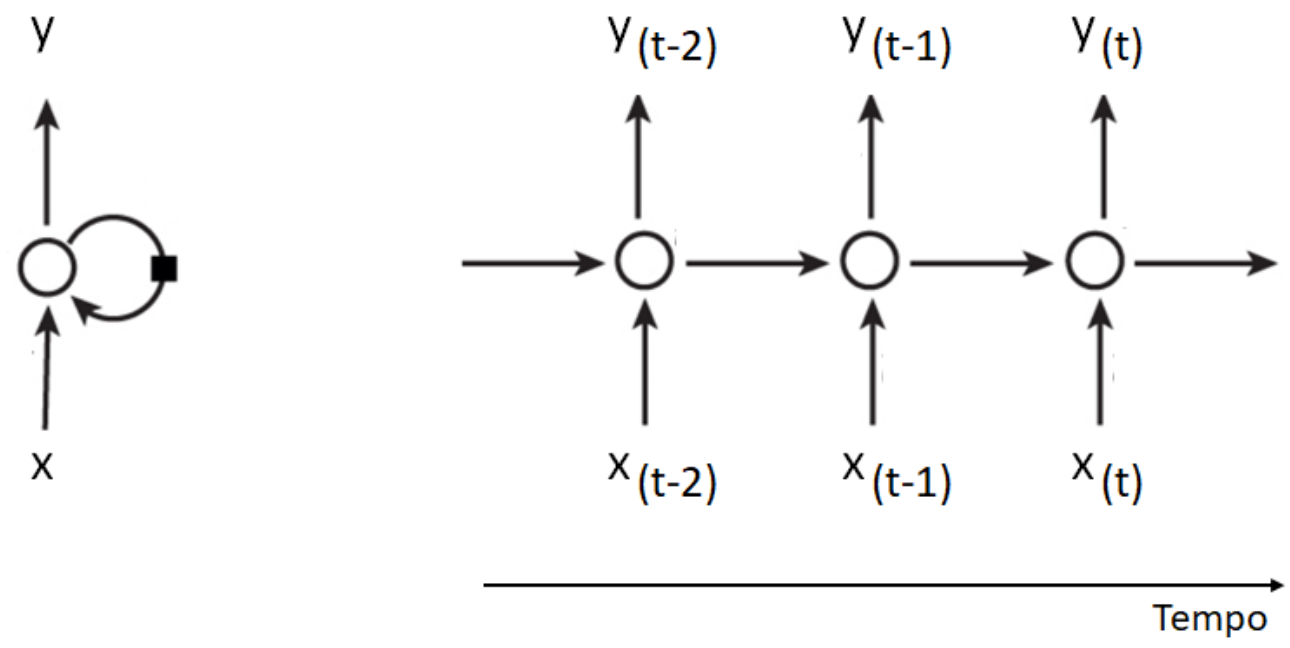

Fonte: GERON (2009).

\subsubsection{Long Short Term Memory (LSTM)}

A rede LSTM é um tipo de rede neural recorrente que possui a capacidade de armazenar informações por um longo período ao analisar uma sequencia temporal. Os pontos de memória de uma rede LSTM são denominadas células, essas estruturas são capazes de identificar quais informações devem ser armazenadas ou descartadas pela rede (SANTOS, 2019). A arquitetura básica de uma célula LSTM é apresentada na Figura Figura 25.

Figura 25 - Célula LSTM

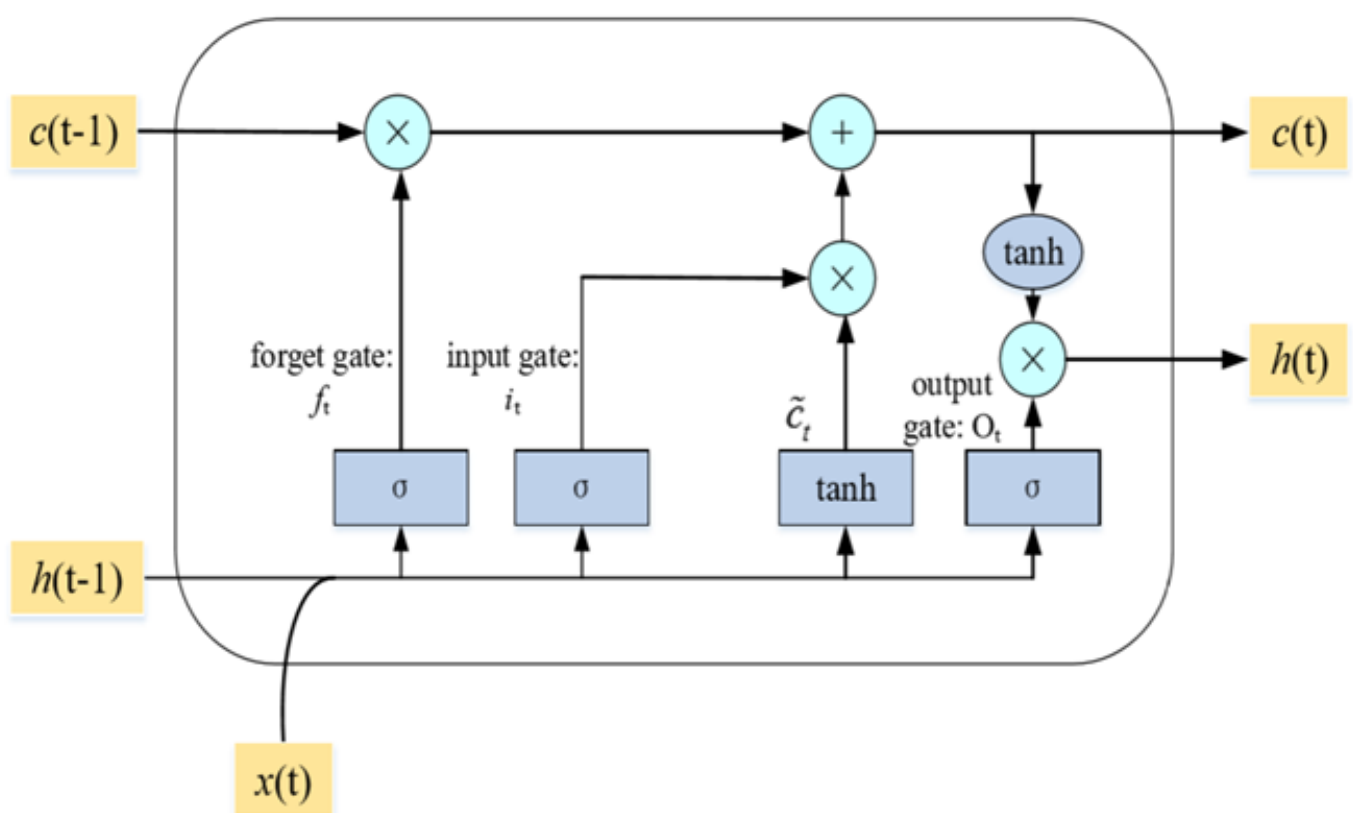

Fonte: Yuan, Wang e Li (2019).

O funcionamento da célula LSTM é descrito a seguir: O vetor de entrada atual x(t) e o 
estado de curto prazo anterior $\mathrm{h}(\mathrm{t}-1)$ são fornecidos para quatro camadas diferentes: A camada principal produz $\mathrm{g}(\mathrm{t})$ analisa as entradas $\mathrm{x}(\mathrm{t})$ e estado anterior $\mathrm{h}(\mathrm{t}-1)$. $\mathrm{E}$ as outras três camadas são portões que controlam diferentes comportamentos (GERON, 2009):

- O portão de esquecimento (forget gate) controla, através de sua função logística $\sigma$, quais partes do estado de longo prazo devem ser apagadas, retornando valores no intervalo entre 0 e 1.

- O portão de entrada (input gate) controla quais partes devem ser adicionadas ao estado de longo prazo.

- O portão de saída (output gate) controla as partes que devem ser lidas e exibidas no estado de tempo atual.

\subsubsection{ConvLSTM}

A ConvLSTM também é caracterizada por uma camada recorrente. Ela funciona de forma análoga a uma LSTM, mas todas as operações de multiplicação interna de matrizes que aconteceriam na LSTM são substituídas por convoluções (XAVIER, 2019).

A Figura 26 representa uma célula de uma rede ConvLSTM.

Figura 26 - Célula ConvLSTM

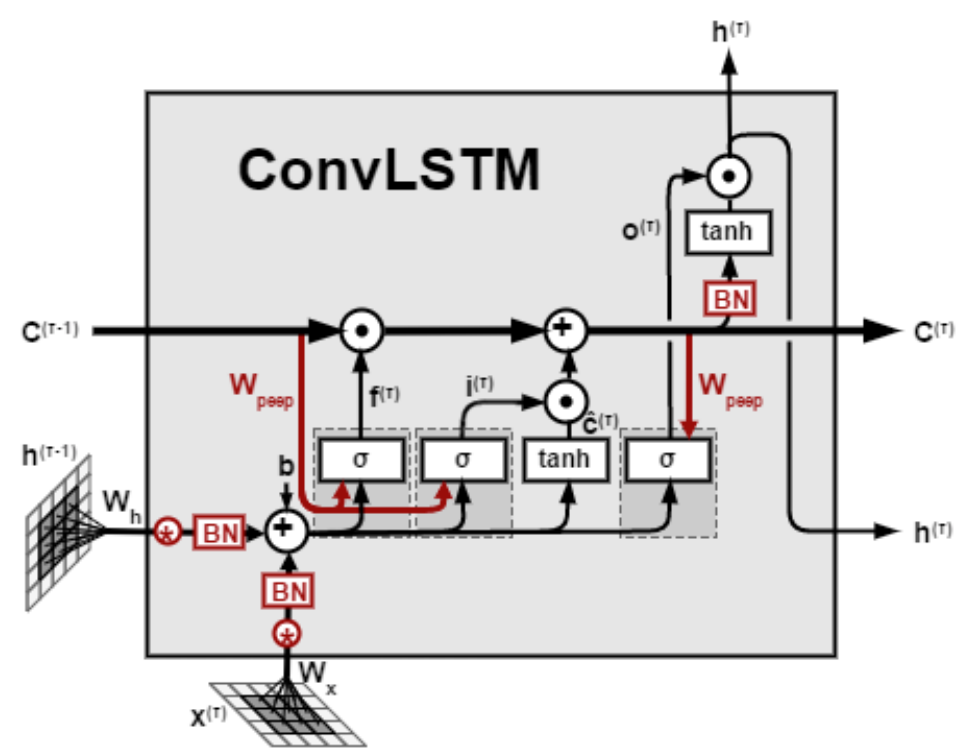

Fonte: Xavier (2019).

\subsection{Métricas de avaliação dos resultados}

Nesta seção são apresentadas as métricas utilizadas para avaliação dos diferentes métodos de aprendizagem. 


\subsubsection{Matriz de Confusão}

A matriz de confusão, ilustrada na Figura 27, é uma ferramenta importante pois permite analisar de forma rápida o desempenho de cada sistema. Os valores que compõem a matriz são obtidos fornecendo os segmentos do conjunto de teste ao método de classificação e comparando sua predição com a classe correta de cada segmento.

Figura 27 - Matriz de Confusão

\begin{tabular}{|c|c|c|c|}
\hline & \multicolumn{2}{|c|}{ Detectada } \\
\hline & & Sim & Não \\
\hline \multirow{2}{*}{ ๘ีّ } & Sim & $\begin{array}{c}\text { Verdadeiro Positivo } \\
\text { (VP) }\end{array}$ & $\begin{array}{c}\text { Falso Negativo } \\
\text { (FN) }\end{array}$ \\
\hline & Não & $\begin{array}{l}\text { Falso Positivo } \\
\text { (FP) }\end{array}$ & $\begin{array}{c}\text { Verdadeiro Negativo } \\
\text { (VN) }\end{array}$ \\
\hline
\end{tabular}

Fonte: Rodrigues (2019).

Após a comparação os valores são classificados em quatro possíveis opções:

- Verdadeiro Positivo (VP): segmentos que pertencem a classe positiva e foram classificados como positivos

- Falso Positivo (FP): segmentos que pertencem a classe negativa e foram classificados como positivos.

- Falso Negativo (FN): segmentos que pertencem a classe positiva e foram classificados como negativos.

- Verdadeiro Negativo (VN): segmentos que pertencem a classe negativa e foram corretamente classificados como negativos.

No caso de classificar os movimentos do cachorro, em que temos múltiplas classes, a matriz de confusão é utilizada ao transformarmos o problema em binário. Para isso analisamos o classificador sob a ótica de uma classe específica por vez, ou seja, dada a entrada X, o resultado pertence (SIM) ou não pertence (NÃO) a classe Y? Com isso temos uma matriz de confusão para cada classe e então podemos assumir as métricas gerais do classificador como sendo as médias das métricas das classes que o compõem. 


\subsubsection{Acurácia}

É uma medida de desempenho global que a avalia a proporção de classificações corretas, tanto de casos positivos quanto negativos.

$$
\text { Acurácia }=\frac{\text { Total de acertos }}{\text { Total de elementos da amostra }}=\frac{V P+V N}{(V P+F N)+(V N+F P)}
$$

\subsubsection{Precisão}

É a taxa de classificação positiva correta considerando todos os valores preditos como positivos.

$$
\text { Precisão }=\frac{\text { Predição positiva correta }}{\text { Predição positiva }}=\frac{V P}{V P+F P}
$$

\subsubsection{Sensibilidade}

Também conhecido como "recall", é a proporção de verdadeiros positivos em relação ao total de positivos da amostra.

$$
\text { Sensibilidade }=\frac{\text { Predição positiva correta }}{\text { Total de positivos da amostra }}=\frac{V P}{V P+F N}
$$

\subsubsection{F1 Score}

Essa métrica combina precisão e sensibilidade para gerar um indicador da qualidade geral do modelo.

$$
F 1=\frac{2 * \text { Precisão } * \text { Sensibilidade }}{\text { Precisão }+ \text { Sensibilidade }}
$$

\subsubsection{Coeficiente de correlação de Matthews}

O Coeficiente de Correlação de Matthews (MCC), do inglês Matthews Correlation Coefficient, é uma medida de qualidade de classificações binárias que retorna um valor no intervalo fechado [-1,1],onde o valor “ +1 ” indica uma classificação perfeita, "0" indica uma classificação equivalente a que seria feita aleatoriamente, e "-1" uma classificação imprópria, invertida.

$$
M C C=\frac{(V P * V N)+(F P+F N)}{\sqrt{(V P+F P)+(V P+F N)+(V N+F P)+(V N+F N)}}
$$


O MCC, assim como todas as demais métricas apresentadas nesta seção, podem ser generalizadas para problemas que apresentam mais do que duas classes, para isso podem ser utilizadas duas abordagens:

Micro-média (do inglês Micro-Averaging) onde primeiro é feito a soma de todos VP, VN, FP e FN para cada classe, e depois é calculada a medida estatística de interesse.

Macro-média (do inglês Macro-Averaging) onde primeiro é calculada a medida estatística para cada classe individual e depois é calculada a média entre elas. 


\section{5}

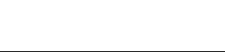

METODOLOGIA

Neste capítulo serão descritos os métodos utilizados para a identificação dos movimentos dos cães. O experimento pode ser divido em três etapas principais:

- aquisição dos sinais de movimento, que foram obtidos por meio de um acelerômetro acoplado na coleira dos cães;

- análise e tratamento dos dados gerados, que consistiu na preparação dos dados para serem inseridos nas redes neurais; e

- treinamento das redes neurais, que teve como resultado final o reconhecimento dos movimentos realizados pelos cães.

\subsection{Sistema de aquisição e transmissão dos dados}

O sistema utilizado para aquisição dos dados, cujo diagrama simplificado é apresentado na Figura 28, consistiu em três elementos:

- Pingente para ser acoplado na coleira do cachorro: o pingente tem como principais componentes eletrônicos um acelerômetro triaxial, memória e bateria não recarregável. Os dados inerciais, que representam os movimentos do cão, são detectados pelo acelerômetro e armazenados na memória, quando há conexão Bluetooth com o celular os dados da memória são enviados para o aplicativo.

- Aplicativo: o aplicativo tem a função de receber os dados inerciais e associa-los a um rótulo, imputado pelo usuário que observa o comportamento do cão e classifica seu movimento em uma das seguintes categorias: "Andando", "Comendo ou Bebendo", "Correndo", "Latindo" e "Sentado". Por conexão com a internet o aplicativo envia os dados para um banco de dados na nuvem. 
- Banco de dados na nuvem: os dados rotulados ficam disponíveis para serem acessados no banco de dados na nuvem.

Figura 28 - Diagrama simplificado do sistema de aquisição de dados

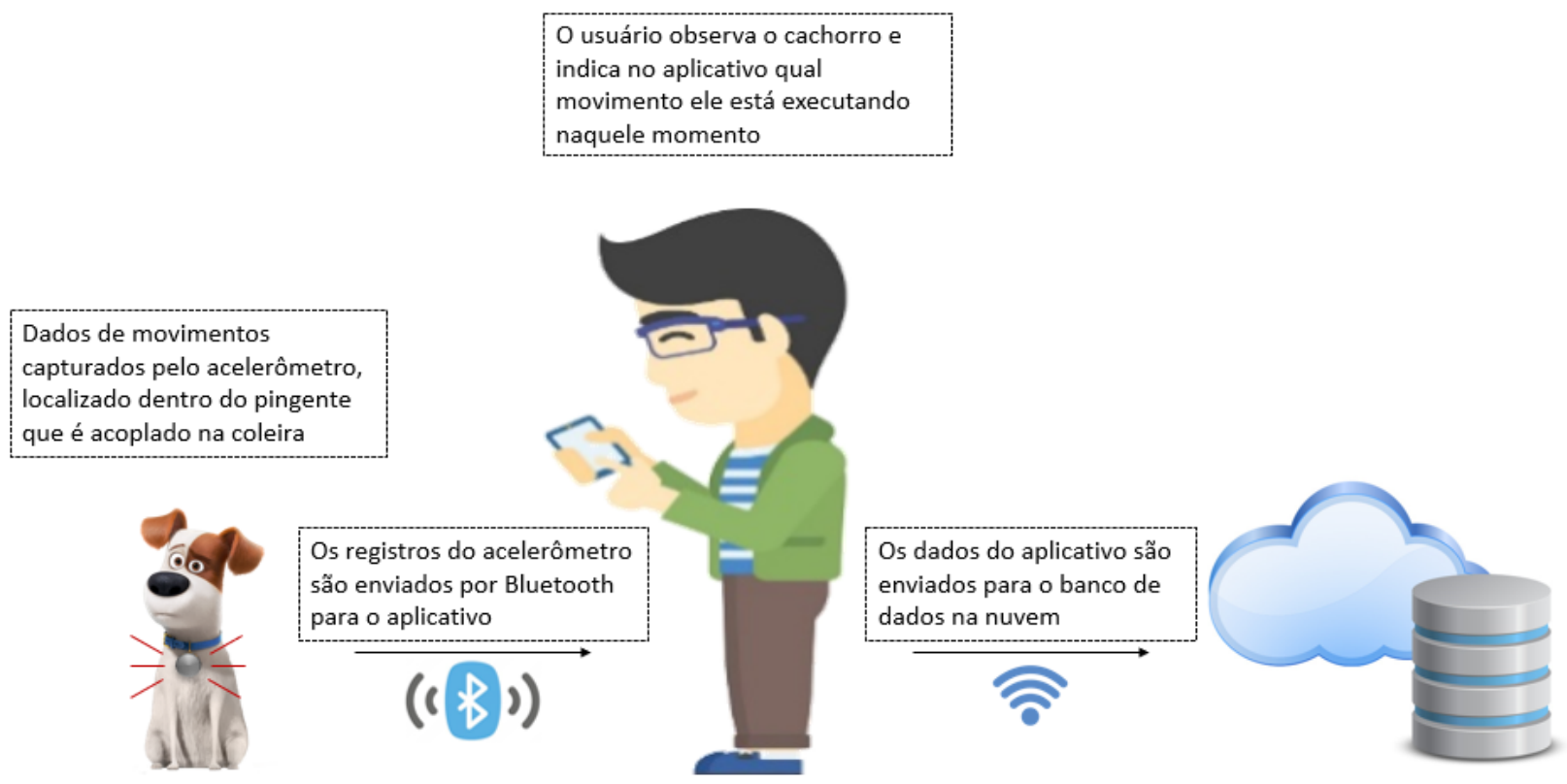

Fonte: Elaborada pelo autor.

O pingente utilizado possui alças para serem acopladas na coleira do cachorro, por este motivo não houve problemas relacionados à sua fixação. Durante o estudo, não houve nenhuma interferência por parte do usuário, com estímulos que pudessem modificar o comportamento normal do cão.

O firmware presente no pingente configura o acelerômetro para uma amostragem contínua dos três eixos à taxa de $10 \mathrm{~Hz}$, que é suficiente para a monitoração dos movimentos rotineiros dos cães, além de manter o consumo de energia em um nível reduzido, aumentando a duração da bateria do pingente.

Baseado no esquema elaborado por JUNIOR et al. (2020), a Figura 29 apresenta o posicionamento do sensor na coleira do cão, e as orientações dos eixos do acelerômetro. 
Figura 29 - Posicionamento dos eixos do acelerômetro na coleira do cão

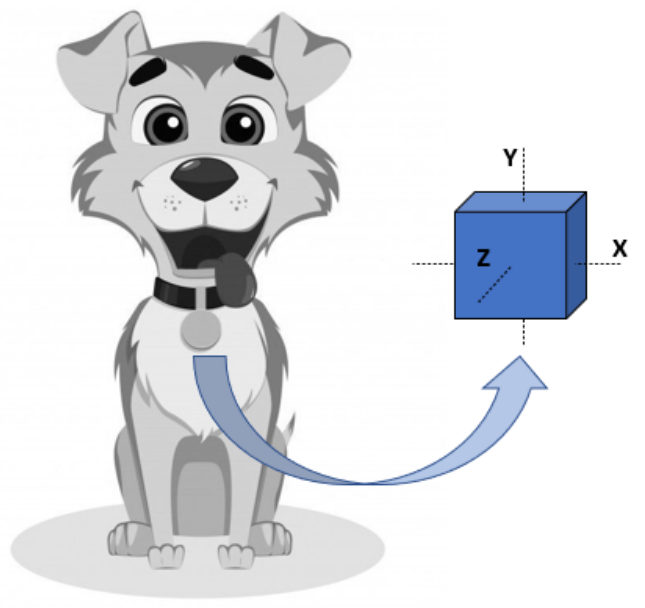

Fonte: Elaborada pelo autor.

\subsection{Cães analisados}

Este estudo analisou uma amostra de 8 cães que localizavam-se na cidade de São Paulo. Os tutores (donos dos cães) informaram que seus cães estavam em bom estado de saúde no período de realização dos testes, e nenhum deles apresentava qualquer anormalidade locomotora. Foram selecionados cães de diferentes raças, idades e sexo, conforme detalhado no Quadro 1.

Quadro 1 - Descrição dos cães participantes deste estudo

\begin{tabular}{cccc}
\hline Identificação & Raça & Sexo & Idade \\
\hline C1 & Boiadeiro Australiano & Fêmea & 5 anos \\
C2 & Spitz Alemão & Macho & 2 anos \\
C3 & Spitz Alemão Anão & Macho & 8 anos \\
C4 & Akita Americano & Macho & 1 ano \\
C5 & Sem Raça Definida & Fêmea & 5 anos \\
C6 & Maltês & Fêmea & 3 anos \\
C7 & Maltês & Fêmea & 7 anos \\
C8 & Sem Raça Definida & Macho & 12 anos \\
\hline
\end{tabular}

Fonte: Elaborada pelo autor.

\subsection{Protocolo de coleta de dados}

Os tutores receberam instruções sobre como acoplar o pingente na coleira do cão, de modo que o pingente ficasse posicionado próximo ao pescoço e sem causar desconfortos, conforme visto na Figura 29. Os movimentos classificados são apresentados no Quadro 2. 
Quadro 2 - Descrição dos cinco comportamentos analisados

\begin{tabular}{l|l}
\hline Comportamento & Descrição \\
\hline Andando & $\begin{array}{l}\text { Locomoção com deslocamento das patas para frente e para } \\
\text { trás }\end{array}$ \\
\hline Correndo & $\begin{array}{l}\text { Locomoção com deslocamento rápido, onde as patas trasei- } \\
\text { ras ultrapassam o meio do corpo }\end{array}$ \\
\hline Comendo ou Bebendo & $\begin{array}{l}\text { O cachorro come ou bebe algo de uma tijela, e sua posição é } \\
\text { parado com a cabeça abaixada em direção à tijela }\end{array}$ \\
\hline Latindo & $\begin{array}{l}\text { Vocalização de sons altos, onde na maioria das vezes a ca- } \\
\text { beça está elevada e posicionada para frente }\end{array}$ \\
\hline Sentado & $\begin{array}{l}\text { Parte traseira do corpo em contato com o chão, com movi- } \\
\text { mentos apenas da cabeça e da própria respiração }\end{array}$ \\
\hline
\end{tabular}

Fonte: Elaborada pelo autor.

A Figura 30 apresenta uma ilustração do aplicativo utilizado pelos usuários para rotular os movimentos dos cães.

Figura 30 - Ilustração do aplicativo utilizado para a classificação dos movimentos

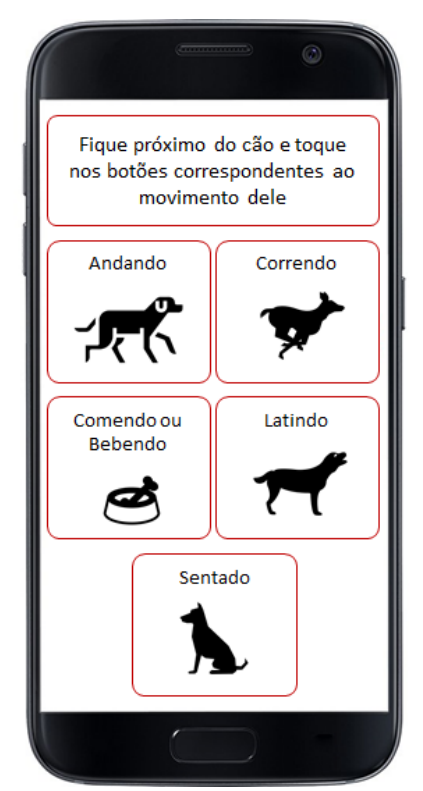

Fonte: Elaborada pelo autor.

\subsection{Amostragem dos movimentos}

Neste trabalho foram utilizados algoritmos de reconhecimento de padrões baseados em aprendizado supervisionado, onde o ajuste dos parâmetros livres relacionados a cada tipo de algoritmo foi feito a partir de uma base de dados de treinamento. Essa base de dados foi formada a partir dos sinais obtidos durante todas as diferentes movimentações previstas para o 
reconhecimento, cada qual associado à informação da classificação esperada, constituindo pares de informações do tipo entrada e saída esperados.

O registro do comportamento do cão feito pelo tutor através do aplicativo poderia resultar em alguns erros ou imprecisões, pois existe o tempo de reação entre o usuário perceber o comportamento do cão e apertar o botão correspondente no aplicativo. Também há imprecisões no momento de finalizar o registro do movimento, pois o cachorro muda de comportamento rapidamente e o usuário leva um tempo para apertar o botão e registrar o fim da atividade no aplicativo. Dessa forma, para minimizar os erros associados ao tempo de reação do usuário, foram descartadas as 10 primeiras e 10 ultimas amostras de cada registro de movimento.

As informações recebidas do sensor e do usuário supervisor foram armazenadas pelo aplicativo e enviadas para o banco de dados, contendo um índice de contagem de amostras, a data e hora em que a amostra foi obtida, os valores da aceleração nos eixos x, y e z e a classificação esperada.

\subsection{Segmentação dos dados}

Para que as amostras de aceleração previamente coletadas sejam processadas e classificadas, primeiramente é necessário que o conjunto de dados seja segmentado em pequenas quantidades, as quais recebem o nome de janela de amostras.

A Figura 31 ilustra um exemplo de 60 amostras por janela com uma sobreposição de $50 \%$, ou seja, cada janela possuiu metade das amostras da janela anterior, evitando-se com isso que alguma atividade localizada na junção entre duas janelas fosse perdida.

Figura 31 - Segmentação dos dados em janelas de 60 amostras com 50\% de sobreposição

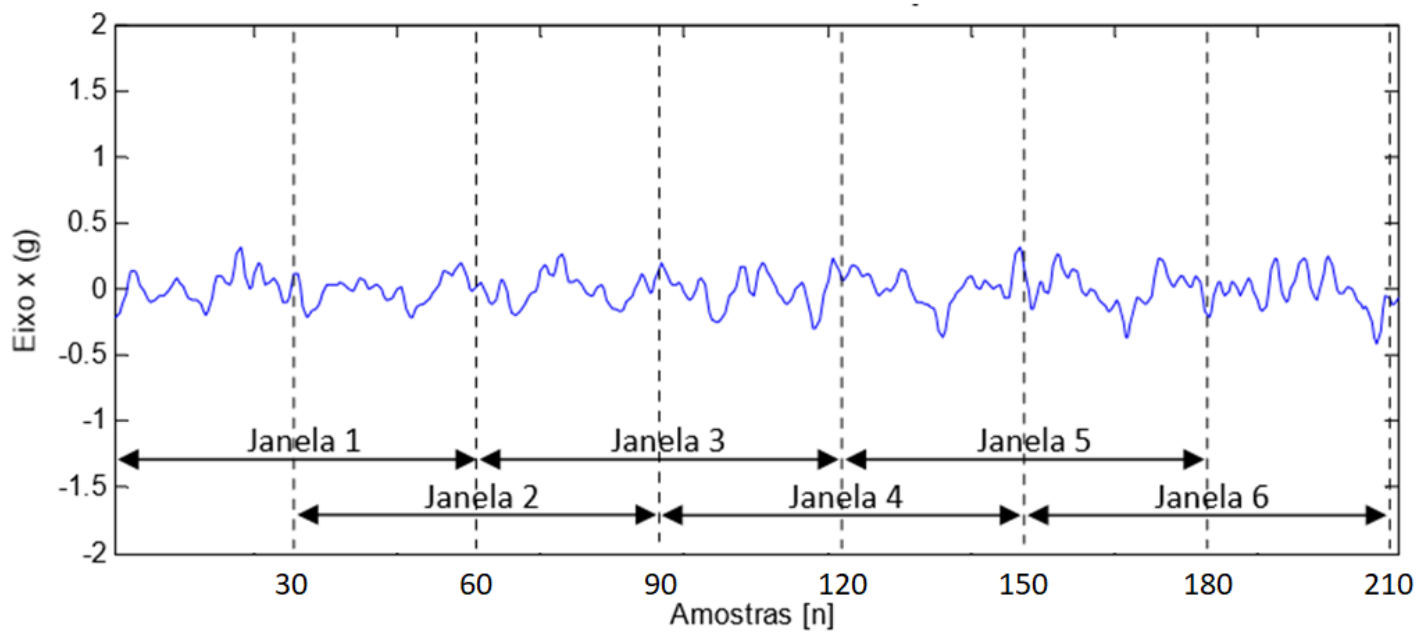

Fonte: Elaborada pelo autor. 

Neste capítulo são apresentados os resultados obtidos com a realização da metodologia proposta no capítulo anterior. Primeiramente serão apresentados os sinais coletados durante o experimento, permitindo uma visão geral dos mesmos, posteriormente será apresentado um experimento feito com a variação dos parâmetros da CNN e, por fim, será apresentado o desempenho de cada uma das arquiteturas de redes neurais (CNN, CNN LSTM, ConvLSTM) treinadas.

\subsection{Pré-processamento dos dados}

Conforme apresentado no Capítulo anterior, as classificações dos movimentos dos cães utilizadas para o aprendizado supervisionado foram obtidas através dos tutores por meio de observação direta, e indicação no aplicativo do movimento realizado pelo cão. Ao utilizar esta abordagem, é necessário considerar o tempo de reação do indivíduo, que consiste no intervalo de tempo entre a geração de um estímulo visual ou audível e uma ação motora. Este tempo está na ordem de milésimos de segundos, e pode variar de pessoa para pessoa de acordo com o estado emocional, sexo, idade, condicionamento físico, etc. Neste trabalho foi considerado um tempo de reação de 1 segundo, e por isso para cada amostra de movimento classificado foram desconsiderados o primeiro e o último segundos.

Segundo o teorema de amostragem de Nyquist, em problemas de classificação de movimentos a partir de dados do acelerômetro, é necessário que a frequência de amostragem seja pelo menos duas vezes maior que o movimento observado. Dessa forma, como foi utilizada uma frequência de $10 \mathrm{~Hz}$ para a coleta de dados, o critério utilizado para uma amostra de movimentos classificados foi ter a duração de pelo menos 80 segundos, sendo que amostras inferiores a esta quantidade foram descartadas. As amostras de movimentos obtidas após o pré-processamento são apresentadas no Quadro 3. 
Quadro 3 - Movimentos reconhecidos pelo sistema

\begin{tabular}{c|ccccc}
\hline Identificação & Andando & Correndo & Comendo ou Bebendo & Latindo & Sentado \\
\hline C1 & 1051 & 1192 & 755 & 869 & 786 \\
C2 & 919 & 941 & 903 & 754 & 1055 \\
C3 & 1086 & 720 & 947 & 665 & 875 \\
C4 & 842 & 915 & 813 & 1180 & 843 \\
C5 & 842 & 540 & 1195 & 857 & 811 \\
C6 & 977 & 815 & 971 & 845 & 968 \\
C7 & 808 & 885 & 934 & 862 & 972 \\
C8 & 635 & 1152 & 642 & 1128 & 850 \\
\hline
\end{tabular}

Fonte: Elaborada pelo autor.

A Figura 32 apresenta amostras para cada tipo de movimento classificado.

Figura 32 - Sinais representativos dos movimentos
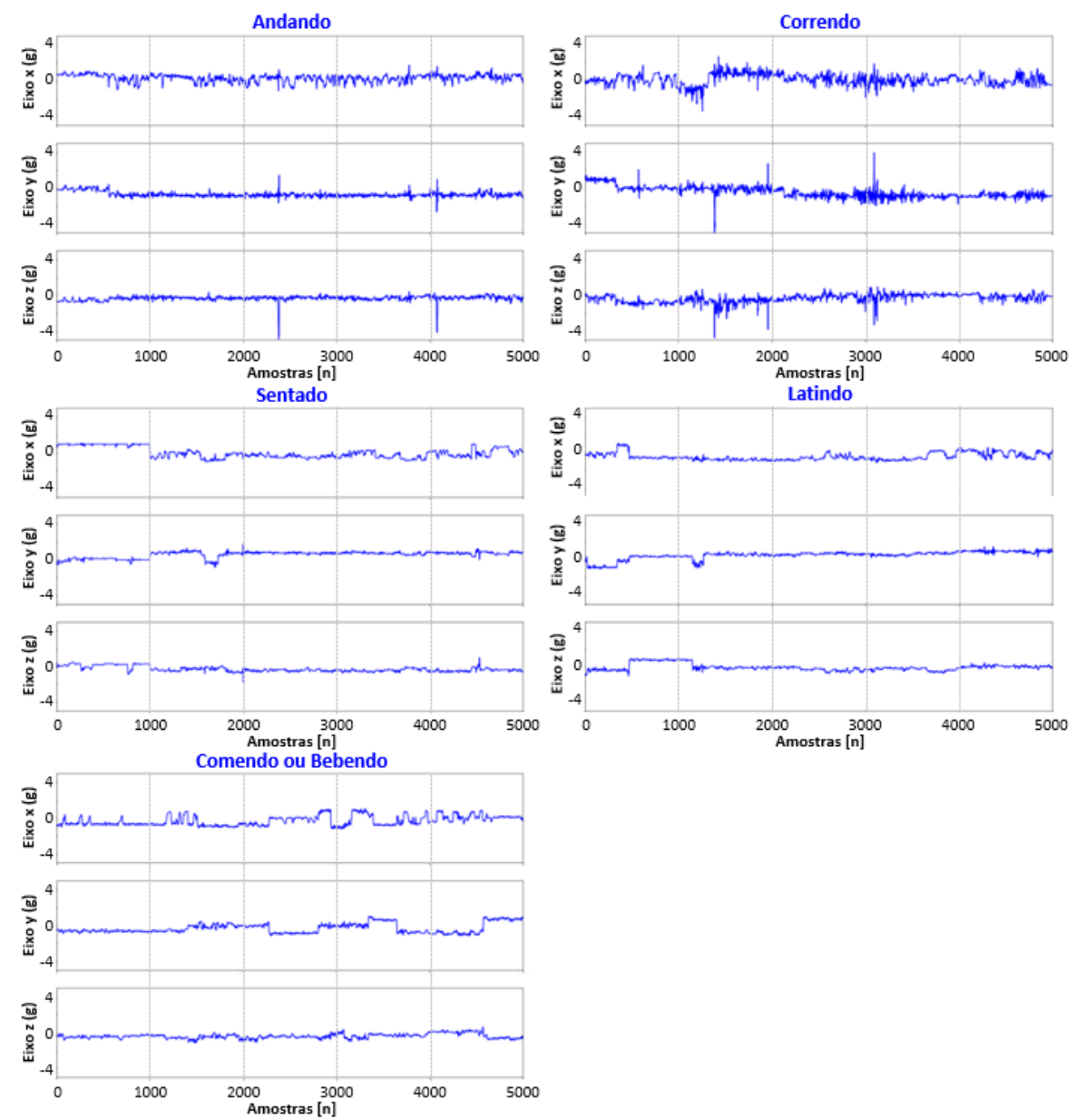

Fonte: Elaborada pelo autor. 


\subsection{Arquitetura das redes neurais utilizadas}

Para o reconhecimento dos movimentos dos cães, foram utilizadas três tipos de arquitetura de redes neurais que combinam camadas convolucionais e camadas totalmente conectadas. As camadas convolucionais são responsáveis por extrair características e fornecer representações abstratas dos dados de entrada. E as camadas totalmente conectadas são responsáveis pela interpretação das características extraídas pelas camadas anteriores. A principal diferença entre a CNN tradicional e as outras duas apresentadas neste estudo é que a CNN LSTM utiliza células LSTM recorrentes nas camadas totalmente conectadas, e a ConvLSTM utiliza células LSTM nas camadas convolucionais. Ao contrário das células padrão, a LSTM possui conexões de feedback, o que faz com que ela seja capaz de processar sequências de dados, ao invés de pontos únicos. A estrutura das redes propostas são apresentadas na Figura 33.

Figura 33 - Diferenças entre as redes propostas
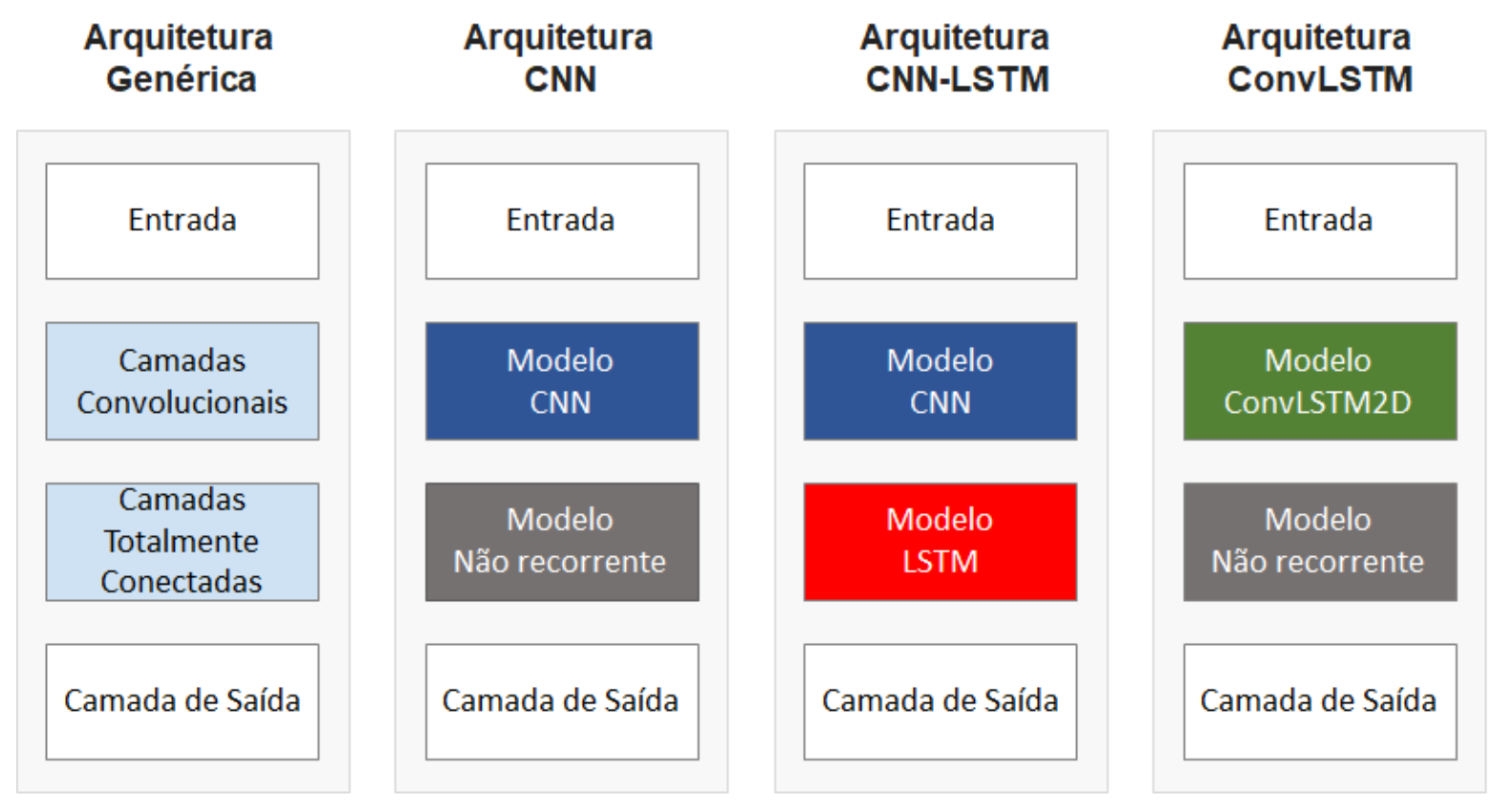

Fonte: Elaborada pelo autor.

Para fins de comparação, foram realizados testes com diferentes topologias da CNN considerando a variação do tamanho da janela deslizante, quantidade de camadas convolucionais e tamanho do filtro da camada convolucional. A partir dos testes, foi verificado como cada um dos parâmetros variantes interferiram no desempenho da rede, e a topologia com o melhor desempenho foi selecionada para comparação com as redes CNN LSTM e ConvLSTM. Dessa forma, a diferença de performance entre os modelos são resultantes da diferença nas arquiteturas e não devido à melhores técnicas de otimização, pré-processamento ou otimizações na rede. 


\subsubsection{Treinamento e teste da CNN}

Foram rodados 10 experimentos para avaliar a performance de cada topologia, onde $80 \%$ dos dados de cada movimento foram utilizados no conjunto de treinamento, e os $20 \%$ restantes no conjunto de teste. As diferentes topologias foram montadas variando os seguintes parâmetros:

- Tamanho da janela deslizante: Janelas de 4s, 6s e 10s

- Número de camadas convolucionais (C): 2 e 4 camadas

- Tamanho do filtro (F): Filtro de tamanhos 3, 5 e 7

O desempenho das diferentes topologias é apresentado na Tabela 1, que trás o valor médio dos indicadores considerando os 10 experimentos.

Tabela 1 - Desempenho das redes neurais considerando a variação dos parâmetros

\begin{tabular}{|c|c|c|c|c|}
\hline Topologia & Acurácia & Precisão & Sensibilidade & $\begin{array}{c}\text { Coef. de } \\
\text { Mathews }\end{array}$ \\
\hline \multicolumn{5}{|c|}{ Janela de 4 segundos } \\
\hline $\mathrm{C}=2, \mathrm{~F}=3$ & 0,7606 & 0,8175 & 0,5965 & 0,7019 \\
$\mathrm{C}=2, \mathrm{~F}=5$ & 0,7547 & 0,8156 & 0,5967 & 0,6945 \\
$\mathrm{C}=2, \mathrm{~F}=7$ & 0,7534 & 0,8157 & 0,5984 & 0,6926 \\
\hline $\mathrm{C}=4, \mathrm{~F}=3$ & 0,7589 & 0,8062 & 0,5728 & 0,7003 \\
$\mathrm{C}=4, \mathrm{~F}=5$ & 0,7547 & 0,8048 & 0,5813 & 0,6953 \\
$\mathrm{C}=4, \mathrm{~F}=7$ & 0,7561 & 0,8068 & 0,5847 & 0,6969 \\
\hline \multicolumn{5}{|c|}{ Janela de 6 segundos } \\
\hline $\mathrm{C}=2, \mathrm{~F}=3$ & 0,7649 & 0,8251 & 0,6111 & 0,7070 \\
$\mathrm{C}=2, \mathrm{~F}=5$ & 0,7678 & 0,8260 & 0,6132 & 0,7109 \\
$\mathrm{C}=2, \mathrm{~F}=7$ & 0,7661 & 0,8262 & 0,6174 & 0,7088 \\
\hline $\mathrm{C}=4, \mathrm{~F}=3$ & 0,7711 & 0,8147 & 0,5896 & 0,7153 \\
$\mathrm{C}=4, \mathrm{~F}=5$ & 0,7883 & 0,8167 & 0,5942 & 0,7366 \\
$\mathrm{C}=4, \mathrm{~F}=7$ & 0,7858 & 0,8177 & 0,6015 & 0,7338 \\
\hline \multicolumn{5}{|c|}{ Janela de 10 segundos } \\
\hline $\mathrm{C}=2, \mathrm{~F}=3$ & 0,7091 & 0,8429 & 0,6332 & 0,6373 \\
$\mathrm{C}=2, \mathrm{~F}=5$ & 0,7105 & 0,8396 & 0,6377 & 0,6395 \\
$\mathrm{C}=2, \mathrm{~F}=7$ & 0,7000 & 0,8376 & 0,6357 & 0,6263 \\
\hline $\mathrm{C}=4, \mathrm{~F}=3$ & 0,7007 & 0,8260 & 0,6065 & 0,6270 \\
$\mathrm{C}=4, \mathrm{~F}=5$ & 0,7007 & 0,8263 & 0,6115 & 0,6272 \\
$\mathrm{C}=4, \mathrm{~F}=7$ & 0,6916 & 0,8258 & 0,6150 & 0,6160 \\
\hline
\end{tabular}

Fonte: Elaborada pelo autor.

\subsubsection{Análise da variação dos parâmetros da CNN}

Conforme apresentado na seção 4.2, a habilidade preditiva da CNN, considerando as diferentes topologias, foi avaliada utilizando as medidas de acurácia, precisão, sensibilidade e 
Coeficiente de Matthews. Cada uma destas medidas fornece uma informação específica sobre a performance da CNN, mas neste trabalho o Coeficiente de Matthews foi eleito o principal indicador devido à sua ampla utilização na área de bioinformática. 


\subsection{Tamanho da janela}

O tamanho da janela deslizante foi o parâmetro que mais influenciou o resultado do coeficiente de Matthews. A Figura 34 apresenta a síntese da Tabela $1 \mathrm{com}$ a distribuição dos resultados com o mesmo tamanho de janela, onde é possível observar que a janela de $6 \mathrm{~s}$ apresentou o melhor desempenho, a janela de 4 s ficou em segundo lugar e a de 10 s apresentou os menores valores para o coeficiente de Matthews.

Figura 34 - Desempenho considerando a variação no tamanho da janela
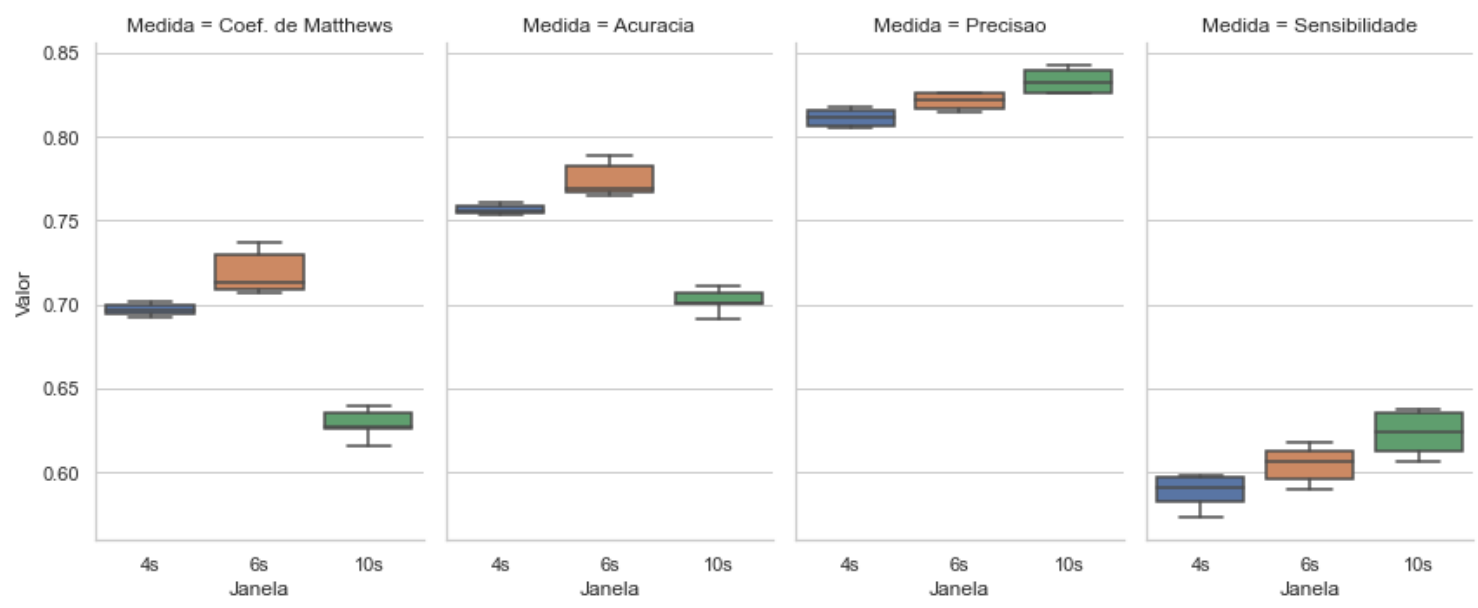

Fonte: Elaborada pelo autor.

\subsection{Número de camadas convolucionais}

A Figura 35 apresenta a distribuição dos resultados considerando o mesmo número de camadas convolucionais. Observa-se que o coeficiente de Mathews e a acurácia não apresentaram diferenças significativas em relação às topologias com 2 e 4 camadas. Mas a precisão e sensibilidade obtiveram resultados melhores com topologia de 2 camadas.

Geralmente o aumento de camadas convolucionais gera um melhor desempenho, pois são extraídas novas características. Entretanto, o tamanho dos mapas de características diminuem a cada operação de convolução, o que pode dificultar a identificação de padrões. 
Figura 35 - Desempenho considerando a variação na quantidade de camadas convolucionais
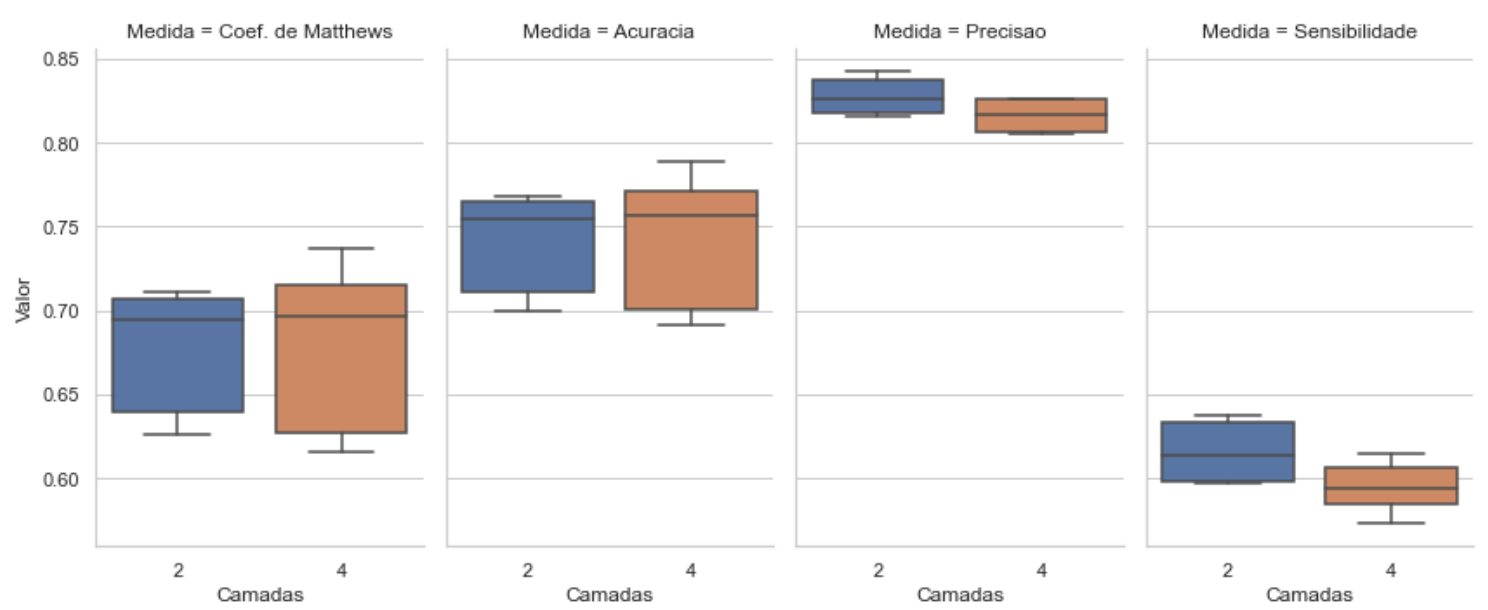

Fonte: Elaborada pelo autor.

\subsection{Tamanho do filtro}

As topologias considerando tamanhos de filtros iguais 3, 5 e 7 não apresentaram diferença significativa de desempenho, conforme mostra a Figura 36.

Figura 36 - Desempenho considerando a variação no tamanho do filtro
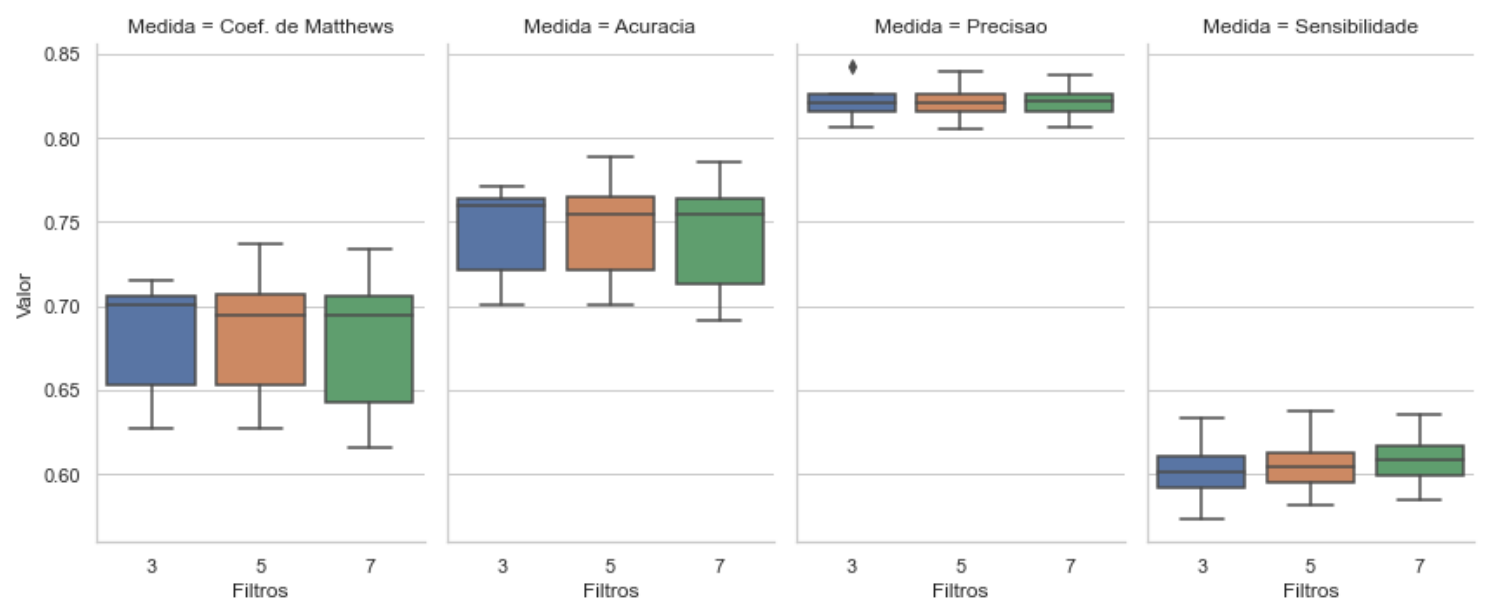

Fonte: Elaborada pelo autor.

Baseado nos testes realizados, a topologia de CNN escolhida como referência é a que recebe como entrada as janelas com 60 amostras temporais, seguida de 2 camadas convolucionais com 64 filtros, sendo que cada filtro possui 2 pesos e se deslocam com o passo igual a 1, esta topologia detalhada é apresentada no Quadro 4. 
Quadro 4 - Detalhes da arquitetura da rede CNN

\begin{tabular}{|c|c|c|}
\hline \multicolumn{3}{|c|}{ Arquitetura 1: CNN } \\
\hline Camada (tipo) & Formato da saída & Parâmetros \\
\hline Convolucional & (None,60,64) & 1024 \\
\hline Dropout & (None, 60,64) & 0 \\
\hline Convolucional & (None,60,64) & 20544 \\
\hline Dropout & (None,60,64) & 0 \\
\hline Max-Pooling & (None, 30,64 ) & 0 \\
\hline Flatten & (None, 1920) & 0 \\
\hline Dense & (None, 128$)$ & 245888 \\
\hline Dropout & (None, 128$)$ & 0 \\
\hline Dense & (None, 128) & 16512 \\
\hline Dropout & (None, 128$)$ & 0 \\
\hline Dense & (None,5) & 645 \\
\hline
\end{tabular}

Fonte: Elaborada pelo autor.

Entre cada camada convolucional (Convolutional) é utilizado Dropout com probabilidade de $10 \%$ do neurônio propagar o sinal após a primeira e segunda convolução. Após a última convolução é aplicada a operação de Max-Pooling de tamanho 2, reduzindo a dimensão dos features maps pela metade. Com isso passa-se a ter 64 features maps com dimensão igual a 30, os quais são vetorizados na camada Flatten em apenas uma dimensão com 1920 elementos.

Cada elemento é entrada da primeira camada totalmente conectada (Dense), com 128 neurônios. É utilizado Dropout com probabilidade de 50\% do neurônio propagar o sinal. As saídas dos neurônios da primeira camada se ligam com outra de 128 neurônios e novamente é utilizado o mesmo Dropout.

Por último há uma camada com 5 neurônios, a qual é seguida por uma função softmax, que determina as probabilidades de cada classe. A função de ativação utilizada nas camadas convolucionais e nas camadas totalmente conectadas foi a Rectified Linear Unit (ReLU). O método de aprendizado utilizado foi o Adam (Adaptative moment estimation) com taxa de aprendizagem de 0.0001 .

A matriz de confusão com os resultados da rede CNN é apresentada na Tabela 2. 
Tabela 2 - Matriz de confusão para a rede CNN

\begin{tabular}{|c|c|c|c|c|c|c|}
\hline \multicolumn{7}{|c|}{ Classe predita } \\
\hline & 1 & 2 & 3 & 4 & 5 & Acertos \\
\hline 1 & 44 & 0 & 4 & 0 & 0 & 0,92 \\
\hline 2 & 2 & 31 & 3 & 2 & 10 & 0,65 \\
\hline 3 & 9 & 2 & 37 & 0 & 0 & 0,77 \\
\hline 4 & 0 & 3 & 4 & 34 & 6 & 0,72 \\
\hline 5 & 0 & 3 & 0 & 5 & 40 & 0,83 \\
\hline
\end{tabular}

Fonte: Elaborada pelo autor.

\subsubsection{Treinamento e teste da CNN LSTM}

A arquitetura de rede CNN LSTM pode ser interpretada como dois submodelos: o modelo CNN para extração das características e o modelo LSTM para interpretação das características através do tempo. A arquitetura utilizada neste estudo é apresentada no Quadro 5.

Quadro 5 - Detalhes da arquitetura da rede CNN LSTM

\begin{tabular}{lll}
\hline \multicolumn{3}{c}{ Arquitetura 2: CNN LSTM } \\
\hline Camada (tipo) & Formato da saída & Parâmetros \\
\hline Convolucional (TimeDistributed(Conv1D)) & (None,None,9,64) & 448 \\
Dropout & (None,None,9,64) & 0 \\
Convolucional (TimeDistributed(Conv1D)) & (None,None,8,64) & 8256 \\
Dropout & (None,None,8,64) & 0 \\
Max-Pooling (TimeDistributed(MaxPooling1D)) & (None,None,3,64) & 0 \\
Flatten (TimeDistributed(Flatten)) & (None,None,192) & 0 \\
LSTM & (None,None,128) & 164352 \\
Dropout & (None,None,128) & 0 \\
LSTM & (None,128) & 131584 \\
Dropout & (None,128) & 0 \\
Dense & (None,5) & 645 \\
\hline
\end{tabular}

Fonte: Elaborada pelo autor.

A principal diferença em relação ao modelo apresentado na Subseção 6.2.1 é que agora as camadas totalmente conectadas são constituídas por células LSTM recorrentes, essa estrutura é utilizada para gerenciar séries de dados que são cronologicamente ordenados, como os dados do acelerômetro.

A matriz de confusão com os resultados da rede CNN LSTM é apresentada na Tabela 3. 
Tabela 3 - Matriz de confusão para a rede CNN LSTM

\begin{tabular}{|c|c|c|c|c|c|c|}
\hline \multicolumn{7}{|c|}{ Classe predita } \\
\hline & 1 & 2 & 3 & 4 & 5 & Acertos \\
\hline 1 & 46 & 1 & 1 & 0 & 0 & 0,96 \\
\hline 2 & 1 & 35 & 1 & 2 & 9 & 0,73 \\
\hline 3 & 5 & 6 & 37 & 0 & 0 & 0,77 \\
\hline 4 & 0 & 5 & 0 & 38 & 4 & 0,81 \\
\hline 5 & 0 & 11 & 0 & 3 & 34 & 0,71 \\
\hline
\end{tabular}

Fonte: Elaborada pelo autor.

\subsubsection{Treinamento e teste da da ConvLSTM}

A principal diferença da ConvLSTM em relação aos dois outros modelos apresentados é a recorrência na camada de convolução, pois todas as operações de multiplicação interna de matrizes que aconteceriam em uma LSTM são substituídas por convoluções. A arquitetura da ConvCNN utilizada é apresentada no Quadro 6.

Quadro 6 - Detalhes da arquitetura da rede ConvLSTM

\begin{tabular}{lll}
\hline \multicolumn{3}{c}{ Arquitetura 3: ConvLSTM } \\
\hline Camada (tipo) & Formato da saída & Parâmetros \\
Convolucional (ConvLSTM2D) & (None, 6,1,10,64) & 86016 \\
BN (BatchNormalization) & (None,6,1,10,64) & 256 \\
Dropout & (None,6,1,10,64) & 0 \\
Convolucional (ConvLSTM2D) & (None,6,1,10,64) & 164096 \\
BN (BatchNormalization) & (None,6,1,10,64) & 256 \\
Dropout & (None,6,1,10,64) & 0 \\
Flatten & (None,3840) & 0 \\
Dense & (None,128) & 491648 \\
Dropout & (None, 128) & 0 \\
Dense & (None, 128) & 16512 \\
Dropout & (None,128) & 0 \\
Dense & (None,5) & 645 \\
\hline
\end{tabular}

Fonte: Elaborada pelo autor.

A matriz de confusão com os resultados da rede ConvLSTM é apresentada na Tabela 4. 
Tabela 4 - Matriz de confusão para a rede ConvLSTM

\begin{tabular}{|c|c|c|c|c|c|c|}
\hline \multicolumn{7}{|c|}{ Classe predita } \\
\hline & 1 & 2 & 3 & 4 & 5 & Acertos \\
\hline 1 & 47 & 1 & 0 & 0 & 0 & 0,98 \\
\hline 2 & 1 & 33 & 1 & 3 & 10 & 0,69 \\
\hline 3 & 6 & 1 & 40 & 1 & 0 & 0,83 \\
\hline 4 & 1 & 4 & 0 & 40 & 2 & 0,85 \\
\hline 5 & 0 & 2 & 0 & 4 & 42 & 0,88 \\
\hline
\end{tabular}

Fonte: Elaborada pelo autor.

\subsubsection{Resultados e comparação entre as diferentes redes treinadas}

A Tabela 5 apresenta os desempenhos para cada uma das redes, onde observa-se que a ConvLSTM apresentou os melhores resultados considerando todos os métodos analisados.

Tabela 5 - Análise comparativa entre os métodos

\begin{tabular}{l|lll}
\hline Método & CNN & CNN LSTM & ConvLSTM \\
\hline Coeficiente de Matthews & 0,7109 & 0,7345 & 0,7935 \\
Acurácia & 0,7678 & 0,7858 & 0,8339 \\
Precisão & 0,8260 & 0,850 & 0,8712 \\
Sensibilidade & 0,6132 & 0,6698 & 0,7217 \\
\hline
\end{tabular}

Fonte: Elaborada pelo autor. 

A utilização de acelerômetros para classificação dos movimentos de animais representa uma ferramenta valiosa e complexa, pois é um grande desafio traduzir dados de aceleração em comportamentos biológicos. Neste sentido, este trabalho apresentou uma forma de reconhecer movimentos simples da rotina de cães através de um único acelerômetro triaxial fixado na coleira do cachorro. A classificação remota de movimentos pode ter aplicações tanto comerciais, como a utilização em dispositivos de monitoramento de animais domésticos, quanto para fins acadêmicos e de clínica veterinária.

A utilização de modelos de CNN para a classificação dos movimentos apresentou um desempenho satisfatório, e mesmo com o baixo volume de exemplos no banco de dados, conseguiu atingir um coeficiente de Matthews de 0,71 . Os testes realizados a partir da variação do tamanho da janela deslizante, quantidade de camadas convolucionais e tamanho do filtro da camada convolucional foram interessantes para investigar na prática como cada um destes parâmetros afeta o desempenho da rede.

Outro resultado significativo deste trabalho foi a verificação da melhoria do desempenho da rede com a utilização de uma arquitetura combinada de CNN com LSTM, que apresentou um coeficiente de Matthews de 0,73, e também a melhoria obtida com a rede ConvLSTM, cujo coeficiente de Matthews foi 0,79.

\subsection{Trabalhos Futuros}

São sugeridos os seguintes tópicos para possíveis trabalhos futuros:

\subsubsection{Utilizar câmeras para filmar o comportamento dos cães}

A tarefa de observar o comportamento do cachorro em tempo real e anotar seu comportamento no aplicativo pode trazer alguns erros na classificação, pois os cães mudam de 
comportamento rapidamente e existe um tempo de reação entre o observador notar a alteração do comportamento do cão e clicar no botão correspondente no aplicativo. Para contornar este problema é indicado a gravação dos cães, com posterior classificação dos comportamentos a partir das análises de vídeos.

\subsubsection{Aumentar a variedade de movimentos reconhecidos}

Este trabalho focou no reconhecimento de cinco movimentos simples da rotina dos cães. Entretanto, seria interessante ampliar o estudo para outros movimentos, como por exemplo o de coceira, que tem grande impacto na saúde e bem estar do cão.

\subsubsection{Aumentar o grupo de estudo e raças de cachorro analisadas}

Os cachorros de diferentes raças podem apresentar grande variabilidade em relação a estrutura física e comportamentos, por isso seria interessante a obtenção de uma ampla base de dados com diferentes raças de cães para segmentar os estudos por raça ou porte, por exemplo, e verificar se ocorre alguma diferença significativa. 


\section{REFERÊNCIAS}

ALMEIDA, T. Uma metodologia de reconhecimento de caracteres manuscritos utilizando redes neurais embarcadas. 2014. Citado na página 41.

ALVES, G. Entendendo redes convolucionais (cnns). 2018. Disponível em: <https://medium. com/neuronio-br/entendendo-redes-convolucionais-cnns-d10359f21184>. Citado na página 46.

ARAÚJO, F.; CARNEIRO, A. C.; SILVA, R. R. Redes neurais convolucionais com tensorflow: Teoria e prática. [S.1.]: III Escola Regional de Informática do Piauí. Livro Anais - Artigos e Minicursos, 2017. v. 1. 382-406 p. Citado nas páginas 47 e 48.

BORCHELT, P.; VOITH, V. Diagnosis and treatment of separation-related behavior problems in dogs. Veterinary Clinics of North America: Small Animal Practice, 1982. Disponível em: <https://doi.org/10.1016/S0195-5616(82)50106-4>. Citado na página 25.

BRUXEL, Y. Sistema para análise de impacto na marcha humana. Universidade Federal do Rio Grande do Sul - Departamento de Engenharia Elétrica, 2010. Citado na página 31.

CARON-LORMIER, G.; ENGLAND, G.; GREEN, M.; ASHER, L. Using the incidence and impact of health conditions in guide dogs to investigate healthy ageing in working dogs. The Veterinary Journal, 2016. Disponível em: <https://doi.org/10.1016/j.tvj1.2015.10.046>. Citado na página 25.

EBERMAM, E.; KROHLING, R. A. Uma introdução compreensiva às redes neurais convolucionais: Um estudo de caso para reconhecimento de caracteres alfabéticos. Revista de Sistemas de Informação da FSMA, p. 49-59, 2018. Disponível em: <http://www.fsma.edu.br/si/edicao21/ FSMA_SI_2018_1_Principal_08.pdf>. Citado na página 48.

FARIA, E. L. Redes neurais convolucionais e mÁquinas de aprendizado extremo aplicadas ao mercado financeiro brasileiro. Universidade Federal do Rio de Janeiro, 2018. Disponível em: <http://hdl.handle.net/11422/11418>. Citado nas páginas 43, 44, 45, 47 e 49.

FITBARK. DOG GPS HEALTH TRACKERS. 2020. Disponível em: <https://www.fitbark. com/>. Acesso em: 17/07/2020. Citado nas páginas 36 e 37.

FORSYTHE, P. Acute otitis externa: the successful first-opinion ear consultation. In Practice, 2016. Disponível em: <http://dx.doi.org/10.1136/inp.i412>. Citado na página 25.

GERENCSÉR, L.; VÁSÁRHELYI, G.; NAGY, M.; VICSEK, T.; MIKLóSI, A. Identification of behaviour in freely moving dogs (canis familiaris) using inertial sensors. PLoS One, 2013. Disponível em: <https://doi.org/10.1371/journal.pone.0077814>. Citado na página 26.

GERON, A. Mãos à Obra: Aprendizado de Máquina com Scikit-Learn TensorFlow. Rio de Janeiro: Alta Books, 2009. Citado nas páginas 42, 49, 50 e 51.

GOODFEllow, I.; BENGIO, Y.; COURVILlE, A. Deep Learning. [S.1.]: The MIT Press, 2016. Citado na página 44. 
GRISOLIO, A. P. R.; PICINATO, M. A. C.; NUNES, J. O. R.; CARVALHO, A. A. B. O comportamento de cães e gatos: sua importância para a saúde pública. Revista de Ciência Veterinária e Saúde Pública, v. 4, n. 1, p. 117-126, 2017. Citado na página 30.

GUPTILL, L.; GLICKMAN, L.; GLICKMAN, N. Time trends and risk factors for diabetes mellitus in dogs: analysis of veterinary medical data base records (1970-1999). The Veterinary Journal, 2013. Disponível em: <https://doi.org/10.1016/S1090-0233(02)00242-3>. Citado na página 25.

Hafemann, L. G.; Oliveira, L. S.; Cavalin, P. R.; Sabourin, R. Transfer learning between texture classification tasks using convolutional neural networks. In: 2015 International Joint Conference on Neural Networks (IJCNN). [S.1.: s.n.], 2015. p. 1-7. Citado na página 45.

HAYKIN, S. Redes Neurais: Princípios e Práticas. [S.1.]: Ed. Bookman, 2007. Citado na página 40.

HUBEL, D. H.; WIESEL, T. N. Receptive fields, binocular interaction and functional architecture in the cat's visual cortex. The Journal of Physiology, v. 160, n. 1, p. 106-154, 1962. Disponível em: <https://physoc.onlinelibrary.wiley.com/doi/abs/10.1113/jphysiol.1962.sp006837>. Citado na página 42.

IBGE, I. B. d. G. e. E. Pesquisa Nacional de Saúde 2013: percepção do estado de saúde, estilos de vida e doenças crônicas - Brasil, Grandes Regiões e Unidades da Federação. Rio de Janeiro: Instituto Brasileiro de Geografia e Estatística, 2014. Disponível em: <https: //biblioteca.ibge.gov.br/visualizacao/livros/liv94074.pdf>. Citado na página 25.

INVENSENSE INC. High Performance 6-Axis MEMS MotionTracking Device. [S.1.], 2016. Rev. 1.0. Citado na página 34.

JUNIOR, A. F.; GARCIA, L. M.; PERDONÁ, G. S. C.; MARANHO, D. A. Measurement of pelvic retroversion during hip flexion: Evaluation with accelerometers. Acta Ortopédica Brasileira, v. 28, n. 2, 2020. Disponível em: <https://doi.org/10.1590/1413-785220202801227237>. Citado nas páginas 34 e 56.

KARPATHY, A. Convolutional neural networks for visual recognition. [s.n.], 2017. Disponível em: <http://cs231n.github.io/convolutional-networks/>. Citado nas páginas 44 e 46.

LINK. GPS Smart Collars for Dogs. 2020. Disponível em: <https://www.linkakc.com/>. Acesso em: 17/07/2020. Citado na página 37.

LOPES, K. R. F.; SILVA, A. R. ConsideraÇÕes sobre a importÂncia do cÃo domÉstico (canis lupus familiaris) dentro da sociedade humana. Acta Veterinaria Brasilica, v. 6, n. 3, p. 177-185, 2012. Citado na página 29.

MAALEJ, R.; KHERALLAH, M. Improving the dblstm for on-line arabic handwriting recognition. Multimedia Tools and Applications, 2020. Disponível em: < https://doi.org/10.1007/ s11042-020-08740-w>. Citado na página 40.

MCCULLOCH, W. S.; PITTS, W. A logical calculus of the ideas immanent in nervous activity. The bulletin of mathematical biophysics, v. 5, 1943. Disponível em: <https://doi.org/10.1007/ BF02478259>. Citado na página 39. 
MICHEL, K.; BROWN, D. Determination and application of cut points for accelerometer-based activity counts of activities with differing intensity in pet dogs. American Journal of Veterinary Research, 2011. Disponível em: <https://doi.org/10.2460/ajvr.72.7.866>. Citado na página 25.

MILIONE, D. Como identificar quando meu cão ou gato está doente? https://www.acessa.com/animais/arquivo/artigo/2019/09/04-como-identificar-quandomeu-cao-gato-esta-doente/, 2019. Citado na página 25.

MILLS, D. S.; MARCHANT-FORDE, J. N.; MCGREEVY, P. D.; MORTON, D. B.; NICOL, C. J.; PHILLIPS, C. J. C.; SANDøE, P.; R., S. R. The encyclopedia of applied animal behaviour and welfare. Oxford University Press, 2010. Citado na página 30.

MIYAZAKI, C. K. Redes neurais convolucionais para aprendizagem e reconhecimento de objetos 3d. Universidade de São Paulo, 2017. Disponível em: <http://www.tcc.sc.usp.br/tce/ disponiveis/18/180500/tce-22022018-121624/?\&lang=br>. Citado na página 45.

NIELSEN, M. Neural Networks and Deep Learning. [s.n.], 2016. Disponível em: <http: //neuralnetworksanddeeplearning.com>. Citado na página 45.

PETPACE. PetPace Smart-Sensing Collar. 2020. Disponível em: <https://petpace.com/ smart-sensing-collar/>. Acesso em: 17/07/2020. Citado na página 38.

RHODIN, M.; BERGH, A.; GUSTAS, P.; ALVAREZ, C. G. Inertial sensor-based system for lameness detection in trotting dogs with induced lameness. The Veterinary Journal, 2017. Disponível em: <https://doi.org/10.1016/j.tvj1.2017.02.004>. Citado na página 26.

RODRIGUES, V. Métricas de Avaliação: acurácia, precisão, recall... quais as diferenças? 2019. Disponível em: <https://medium.com/@ vitorborbarodrigues/m\%C3\%A9tricas-de-avalia\% $\mathrm{C} 3 \% \mathrm{~A} 7 \% \mathrm{C} 3 \% \mathrm{~A} 30-$ acur\%C3\%A1cia-precis\%C3\%A3o-recall-quais-as-diferen\%C3\% A7as-c8f05e0a513c>. Acesso em: 23/07/2020. Citado na página 52.

SAINATH, T. N.; VINYALS, O.; SENIOR, A.; SAK, H. Convolutional, long short-term memory, fully connected deep neural networks. p. 4580-4584, 2015. Citado na página 26.

SANTOS, G. Uma aplicaÇÃo de redes neurais recorrentes do tipo lstm À previs Ão dos preÇos de curto prazo do mercado de energia elÉtrica brasileiro. Fundação Getúlio Vargas - Escola de Economia de São Paulo, 2019. Citado na página 50.

SCHEIBE, K.; GROMANN, C. Application testing of a new three-dimensional acceleration measuring system with wireless data transfer (was) for behavior analysis. Behavior Research Methods, v. 38, p. 427-433, 2006. Disponível em: <https://doi.org/10.3758/BF03192796>. Citado na página 29.

SEARA, C. O acelerômetro. Universidade Federal do Ceará - SEARA DA CIÊNCIA, 2019. Disponível em: <https://seara.ufc.br/pt/tintim-por-tintim/tecnologia/o-acelerometro/>. Acesso em: 17/07/2020. Citado nas páginas 32 e 34.

SILVA, F. G. Reconhecimento de movimentos humanos utilizando um acelerômetro e inteligência computacional. Universidade de São Paulo, 2013. Disponível em: <https://www.teses.usp.br/ teses/disponiveis/3/3140/tde-22092014-103901/pt-br.php>. Citado nas páginas 31 e 33.

TATLER, J.; CASSEY, P.; PROWSE, T. A. High accuracy at low frequency: detailed behavioural classification from accelerometer data. The Company of Biologists Ltd I Journal of Experimental Biology, v. 221, 2018. Citado na página 26. 
UIJL, I. den; ÁLVAREZ, C. G.; BARTRAM, D.; DROR, Y.; HOLLAND, R.; COOK, A. External validation of a collar-mounted triaxial accelerometer for second-by-second monitoring of eight behavioural states in dogs. PLoS One, 2017. Disponível em: <https://doi.org/10.1371/journal. pone.0188481>. Citado na página 25.

VARGAS, A. C. G.; CARVALHO, A. M. P.; VASCONCELOS, C. N. Um estudo sobre redes neurais convolucionais e sua aplicação em detecção de pedestres. Proceedings of the XXIX Conference on Graphics, Patterns and Images, n. 1, p. 1-4, 2016. Citado nas páginas 42 e 43 .

WHISTLE. Whistle Tracker for every pet. 2020. Disponível em: <https://www.whistle.com/>. Acesso em: 17/07/2020. Citado na página 36.

XAVIER, A. Uma introdução a ConvLSTM. 2019. Disponível em: <https://medium. com/neuronio-br/uma-introdu\%C3\%A7\%C3\%A3o-a-convlstm-c14abf9ea84a>. Acesso em: 23/07/2020. Citado na página 51.

YUAN, X.; WANG, Y.; LI, L. Nonlinear dynamic soft sensor modeling with supervised long short-term memory network. IEEE Transactions on Industrial Informatics, 2019. Citado na página 50. 


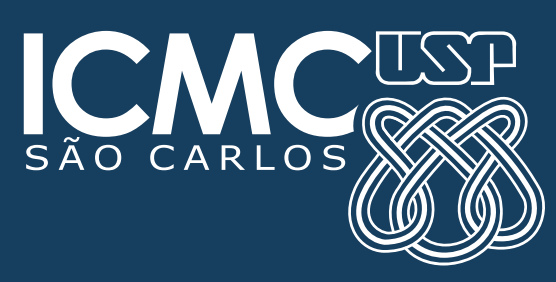

